\title{
AGE AND CONTEXT AFFECT THE STEREOTYPIES OF CAGED MINK
}

\author{
by \\ GEORGIA J. MASON' ${ }^{\mathbf{1}}$ ) \\ (Sub-department of Animal Behaviour, University of Cambridge, Cambridge CB3 8AA)
}

(With 9 Figures)

(Acc. 5-X-1993)

\section{Summary}

The effects of age and context on the stereotypies of caged mink were examined in order to assess the developmental changes undergone by the behaviour, and to find contextspecificity that might suggest its motivational bases. Caged mink perform stereotypies consisting of a variety of movements, most commonly pacing and rearing, running in and out of the nestbox, and stationary head-twirling or nodding. Stereotypies are largely performed as feeding-time approaches, and many mink do not show them at all once fed. Stereotypies become more frequent and less variable with age; and in adults, individuals with the highest levels of stereotypy show the least variable forms of the behaviour and are most likely to perform it in more than one context, i.e. not solely in the pre-feeding period. These data suggest that mink stereotypies become 'established' with age, in the manner described for stereotypies in other species. However, the behaviour of kits does not follow the pattern seen in adults: kits performing stereotypies in more than one context do not have particularly high levels of the behaviour, nor are their stereotypies particularly unvarying. In addition, post-feeding stereotypies are commonly shown even by very young animals. Thus it cannot be the case that mink stereotypies are performed first in the prefeeding situation and only later in other contexts via a process of emancipation. This conclusion is further supported by the finding that the forms of the behaviour often differ pre- and post-feeding. The specific forms and contexts of mink stereotypies suggest certain motivational bases for the behaviour. The rise in stereotypies as feeding time approaches and the sustained levels seen when the animals are not fed indicate hunger as an important factor, and in one dataset, the individuals whose stereotypies were solely pre-feeding used the most Longitudinal movements (i.e. pacing and its variants). This suggests that stereotypies, and pacing movements in particular, may stem from appetitive, food-searching behaviour. In contrast, Stationary movements such as head-twirling are performed more in the hours after feeding, and in one group of mink their levels declined over the pre-feeding period as feeding time approached. The physical appearance of such movements suggests they might be derived from attempts to escape the cage. Thus mink stereotypies are

1) This paper is based on work done as part of my $\mathrm{Ph} \mathrm{D}$. thesis. I am grateful to Patrick Bateson, John Fentress, Mike Mende and Ton Groothus for invaluable discussion and comment, and to Robin GLARK and Gerrit DE JONGE for their help and advice on the farms. I am particularly grateful to the Spelderholt COVP institute in the Netherlands for allowing me use of their facilities. I was supported financially by the Science and Engineering Research Council, and by a Research Fellowship from Clare College, Cambridge University. 
probably seen in a range of contexts because they develop from several different behaviour patterns, with different motivational bases. The link, in adults, between performance in this range of contexts and the degree of establishment of the behaviour may be explained in one of two ways. In one adult group the data suggest that animals with stereotypy in more than one context incorporate the typically post-feeding Stationary movements into their prefeeding behaviour, as if emancipation of this movement had occurred. However, data from the other adult group do not support this hypothesis, and the degree of establishment and the number of contexts in which stereotypies are performed may not be causally linked at all, but instead the independent products of individual propensities to develop stereotypic behaviour. Sex and site differences have yet to be fully explained. Females show consistently higher levels of stereotypy than males, as if perhaps they find the environment more frustrating. There are also enormous differences in the frequency and incidence of the behaviour on the two different sites studied.

\section{Introduction}

A stereotypy is a behaviour pattern that is repetitive, unvarying, and has no obvious goal or function (e.g. Fox, 1965; Hut \& HuTt, 1970; ÖDBerg, 1978; Wiepkema et al., 1983). Stereotypies are often performed by captive animals (for recent reviews see MASON, 1991a, b), and examples include pacing by polar bears (WECHSLER, 1991), bar-chewing by sows (e.g. Wiepkema et al., 1983), and stable-weaving by horses (e.g. KiLEYWorthington, 1983). Stereotypies are interesting theoretically because they are abnormal, both in the sense of having no apparent function and often also in the sense of being seemingly absent from the 'normal', i.e. the healthy and free-living, animal. Furthermore, they are of concern to applied ethologists because they are often associated with poor welfare (e.g. reviewed Mason, $1991 \mathrm{a}, \mathrm{b}$ ).

Many causal factors have been implicated in the development of stereotypies. One cause is high levels of a specific motivation. For example, the stereotypies performed by rodents as feeding time approaches, on a laboratory régime of periodic feeding, seem related to appetitive behaviour (STaddon \& Simmelhag, 1971; Anderson \& Shettleworth, 1977). Likewise the paw-raising stereotypy seen in a male okapi housed next to an inaccessible female seems to have developed from sustained repetition of part of the courtship sequence (ÖDBERG, 1978). In other cases of stereotypy, however, the specific motivational basis is not so clear and the behaviour does not seem to arise from a particular normal behaviour pattern. An example is the body-rocking stereotypy that often appears in young primates reared in isolation (e.g. Draper \& Bernstein, 1963; BERKson, 1968), and which may possibly act as a source of comforting 
stimulation in a barren and asocial environment (STONE, 1964; Berkson, 1967). A wide range of non-specific factors can also often cause stereotypies to be performed once they have passed a certain stage of development. They may then be elicited if the animal is aroused (Berkson \& Mason, 1964; Fentress, 1973, 1976) or physically active (e.g. the stereotypies of voles follow the daily rhythms of general activity; ÖDBERG, 1986). Low behavioural competition can also increase their performance (e.g. Hinde 1962; Duncan \& Wood-Gush, 1974, interpreting the data of KEIPER, 1970).

Stereotypies thus usually develop over time, and their characteristics change as the behaviour becomes more established. They change in two principle ways. First, established stereotypies differ from developing ones in being much more difficult to discourage or interrupt (KILEY-WORTHington, 1977; Cronin et al., 1984; Cooper \& ODderg, 1991), and they are also less variable (Meyer-Holzapfel, 1968; Fentress, 1976; Cronin et al., 1984). The process of establishment may be due to the growing predominance of central control (e.g. Fentress, 1976), in which the central nervous system sends out precise, fixed patterns of instructions to the muscles with no reliance on external factors such as feedback for the control of the behaviour (e.g. Hinde, 1970, p. 26). Central control can develop in frequently-performed behaviour patterns, e.g. in human skills (MARTiniuk, 1976) such as typing. Alternatively, other similar developmental processes may explain the changes undergone by stereotypy, namely those processes underlying the development and form-fixation of displays (Groothuis, 1993), the crystallisation of birdsong (MARLER et al., 1988; Marler, 1991), or the formation of habits (Norman, 1981). These are all superficially similar phenomena, although their underlying mechanisms may well be very different (see Groothuis, 1993 and Mason \& Turner, 1993).

The second way in which stereotypies change as they develop is that they become more readily elicited, so much so that they come to be scen in new circumstances, not just the originally eliciting one (e.g. ÖDBERG, 1978). This uncoupling of behaviour from its original causal factors is known as emancipation (e.g. Groothuis, 1989; reviewed Mason, 1991a, b). Stereotypies may now be performed in the absence of any apparent stress or conflict (KENNES et al., 1988), and they may even be facilitated by stimuli that would have interrupted them earlier in their development 
(Fentress, 1977). Similar changes in the context of performance occur in displays, e.g. the oblique display of the black-headed gull (Groothuis, 1989), and in learnt behaviour patterns that have been often repeated and that then come to be elicited by secondary cues that have become associated with the conditional stimulus (BINDRA, 1959, cited in Hinde, 1970, p. 557; Hall \& Halliday, 1992, p. 153).

Thus overall, because repeated behaviour patterns may become more easy to elicit and also more difficult to interupt, one would expect stereotypies to increase in frequency with age, as well to have lower variability and to be performed in more than one context. High frequencies of performance may also encourage such developmental changes, if the changes are caused by repetition.

This study was aimed at providing a detailed description of the stereotypies of captive mink and the differences between individuals. The purposes of this were several. The forms of the stereotypies (both speciestypical elements and individual idiosyncrasies) might suggest the behaviour patterns from which the behaviour originates. For example, DE Jonge et al. (unpubl.) indicate that some forms of stereotypy are performed more than others when feeding motivation is high, suggesting that different movements are affected differentially by particular motivational states. The contexts in which they are performed might also suggest the motivational bases of the behaviour. Such findings might then indicate aspects of the captive environment that mink find frustrating. In addition, comparing mink of different ages would reveal if the behaviour changes with development in the ways documented in other animals; its changes in context and form would indicate whether establishment and emancipation occur. Such information is necessary to know with which other examples of stereotypies the behaviour of mink can be compared (MAson, 1993); stereotypies are so heterogeneous that one cannot extrapolate from one case to another without such data (MAson, 1991a, 1993).

Caged mink were chosen as subjects as previous research had shown that they often performed stereotypies, and that these differed in frequency and form between individuals (e.g. DE JONGE et al., 1986; HANSEN, 1989; Brldsøe et al., 1990a; Heller, 1990). This individual variation thus provided a potential means of investigating the sources, and also the development, of the behaviour. Mink are also suitable subjects because on farms they are housed in identical conditions in very large numbers. 


\section{Materials and methods}

Subjects and housing.

The American mink, Mustela vison, has been farmed for its fur for $50-80$ generations (Heller, 1989). The subjects for this study were housed on two farms, one in the UK (in 1988 and 1989), and the other in the Netherlands (in 1990). The 1988-1989 study site consisted of a nucleus of about 2000 females, and at the peak of the breeding season housed some 12000 animals. The mink were individually housed outdoors, in cages measuring $0.75 \times 0.35 \times 0.35 \mathrm{~m}$, with wooden nestboxes. As the cages were wire mesh, the mink could see, hear and smell each other. The cages were in long, parallel rows of 200, and each pair of rows was roofed over to form a long shed, the walls of which were left open. Once a day, between 1130 and 1500 hours, a feeding machine was driven along each shed, and an offalbased paste was deposited on each cage-top. Water was provided ad lib.; the mink drank by pressing a nipple on the water pipe running the length of each shed. The first young mink (kits) were born at the end of April, and whelping continued until the end of May. At about two months of age, kits were removed from their mothers and re-housed in male-female pairs. They stayed in pairs until the pelting season in November, when they were six months of age. Adult mink were caged individually.

The Dutch farm was much smaller, having a nucleus of only 500 females. Housing was very similar to the UK study site. However, feeding differed from the UK farm in two respects. The animals were fed twice a day, receiving a small supplementary meal in the morning, between $0830 \& 0930$, and their main meal late in the afternoon, between $1600 \&$ 1700. Also, the food was delivered manually from a hand-pushed trolley.

The most common coat colour strain, Wild Type, was used in this study. Four groups of mink were observed, two groups of adults and two groups of kits. All adult subject animals were females ranging in age from one to four years. 105 were studied in 1988, and 114 in 1989. The kits studied in 1988 ( $5 \mathrm{l}$ females and 48 males) were largely housed in pairs, and were six months old at the time of the study. 1990's kits (44 females and 51 males) were seven months old and had been singly-housed for a week at the time of data collection. Some of the adult females in 1989 had already been observed some months previously. Forty-one had been observed twelve months earlier, as part of 1988's adult dataset, and fifteen had been observed four months earlier as part of 1988's kit dataset.

\section{Measuring stereotypies.}

Method of data collection.

I observed the mink from the shed neighbouring their own, so that my presence would disturb them as little as possible. The mink seemed to pay little attention to quiet activity, and human observation from a neighbouring shed has been shown (through comparison with video-recordings) to have no significant effect on their behaviour (BILDsøE $e t$ al., 1990b; Heller \& Jeppesen, 1990).

Data collection involved scanning and focal sampling (JENSON et al,, 1986; MARTIN \& BAteson, 1986, pp. 48-49). In addition, behaviour patterns seldom observed during systemmatic data collection were recorded as 'rare events' (see Martin \& BAteson, 1986, p. 51 ). When scanning, I moved down the row from one cage to the next in the same order on each successive scan. Observations were never collected less than ten minutes apart, so that they would be reasonably independent. As the row was scanned, instantaneous sampling was used to record behaviour patterns that were identifiable immediately and apparently normal (e.g. eating, sleeping, drinking, grooming, standing or lying alert). However, this was unsuitable for behaviour that was not obviously consummatory, or that involved a sequence of movements which I wanted to observe for repetitiveness. These behaviour patterns were continuously observed for up to 15 seconds. Observation ceased if a regular pattern (three successive repetitions of a movement or sequence of movements) emerged. 
For adult data, the cage row was scanned on average 25 times a day, for 14 days in late March and early April. Observations were made between 0800 and 1730 hours, both before and after feeding. For 1988's adults, observations were also made over one night using a Nightscope image intensifier. The kits of 1988 were observed 20 times at day for 14 days in late November and early December. In 1990, kits were scanned 18 times a day, for 8 days in early December. Only limited observations of post-feeding behaviour were made in 1990, as feeding occurred just before dusk. The kits were scanned for the short time available before it became too dark, and any post-feeding stereotypy seen was recorded as a rare event. In all groups observed, the time of each scan, and of feeding, were always noted.

Assessing the type and nature of stereotypy.

All repetitive sequences of movements with no obvious goal or function were classified as stercotypies. These included sequences involving some unpredictable, occasional elements (e.g. a mink might pace in a regular way, but sporadically perform a rear in one corner of the cage), because over the days of observation it became clear that individual animals always used the same elements in such sequences. Thus the order of the movements might not be predictable in a single focal observation, but an individual's use of a particular combination of movements was highly recurrent from observation to observation, and from day to day.

Each stereotypy was described as fully as possible, with occasional, unpredictable, elements recorded in parentheses. The location was also recorded: i.e. whether at the front, back, left, or right of the cage, or involving the drinker nipple or the cage ceiling.

Some behaviour patterns did not appear entirely normal and goal-directed, but did not have the rhythmicity necessary to be classed as stereotypies. Some of these behaviour patterns involved the movements seen in stereotypies but with no repetition during a 15 second observation, while others involved switches between normal, consummatory activity and stereotypic elements at a rate too great for reliable instantaneous sampling (there might have been a bias towards the most conspicuous behaviour). These types of behaviour were classified as 'Complex' rather than stereotypic.

The type and nature of the stereotypy, and stereotypy-like Complex behaviour, was assessed for each mink in a number of ways. From the data for each animal:

i) the proportion of observations spent in stereotypies, normal activity, inactivity, and Complex behaviour was calculated;

ii) Stereotypy and Complex behaviour were combined into a broader category termed Restless behaviour, and the proportion of observations spent in this was calculated;

iii) the proportion of observations spent in stereotypies that involved three or more unvarying and sequential repetitions during an observation was calculated; such behaviour was termed Rigid stereotypy.

iv) the proportion of stereotypy involving particular movements (described in detail in the Results section) was calculated; and whether a preferred movement occurred in more than half the individual's stereotypy was also noted;

v) the proportion of Restless behaviour made up of stereotypies was calculated, and also the proportion of stereotypies that were Rigid (this last is henceforth called the Rigidity Index).

The variability and morphology scores (iii-v) were only calculated for those animals who had five or more observations of stereotypy. The context of each individual's stereotypy was also recorded, the most clear distinction being between the performance of stereotypies pre- and post-feeding.

In addition, a random 30 animals from each group were selected and their stereotypies examined in more detail. The number of elements used in each stereotypic sequence was counted, and a mean for each individual calculated. From the individual means, an average for each group was calculated. The number of different stereotypic sequences used by each individual was also counted, and again, a group mean calculated. A stereotypic sequence 
was defined as the repeated combination of elements making up a single stereotypy. No distinction was made between a predictably recurrent element and an unpredictably recurrent element; thus 'pace with an occasional rear at one end of the cage' was not considered a different sequence from 'pace with a rear at one end of the cage'. However, such a sequence would be considered different from 'pace, never rearing', and 'pace with a rear at each end of the cage'. Such distinctions are of course essentially arbitrary, but the data they generate should give an impression of the range of stereotypies displayed.

The effects of age.

To see if stereotypies changed with age, four comparisons were made. The female kits observed in 1988 were comparcd with the female adults observed that same year. Within each adult dataset, mink aged between two and four years were combined into one category ('Multiparous'), as there were relatively few mink in each of these older cohorts, and compared with one-year old, primiparous animals. Longitudinal comparisons were also possible for the two groups of mink (some of 1988's kits and some of 1988's adults), from whom additional data were collected in the spring of 1989.

Statistical analysis of the data.

Before statistical analysis, a number of checks were made on the data. Wherc it was difficult to ascertain if enough data had been collected, they were checked for internal reliability with split-half analyses (MARTIN \& BATESON, 1986, p.32). Where correlational analyses were to be performed, scatter plots of the data were examined beforehand to ensure that outliers were not creating or obscuring a significant result, and that non-linear relationships were not passed over. Parametric statistics were only used where the data met the assumptions required (e.g. Siegel \& Castellan, 1988, p. 34). However, transformations of non-normal stereotypy data were impossible as the principle problem was the great number of zeros.

In the Results section, means are presented with their standard deviations for normal data only. For analyses involving 1989's data, females who had also been watched the previous year were excluded (except where otherwise indicated), so that the sample was an independent replicate of the 1988 study. Statistical tests involving Rigid stereotypy, as opposed to those involving the broader Stereotypy measure, are only presented if they gave significant results not found otherwise.

\section{Results}

Results are presented in the following order. The incidence of stereotypies (how many animals performed them) is followed by data on their appearance, i.e. their forms and their variability, and then by data on their frequency. Within each of these sections the stereotypies of adult female mink are first described, as unambiguous stereotypies performed by the bulk of animals on a mink farm, followed by the less developed stereotypies of the kits. Considered next are further data on age differences, including the results of the longitudinal studies of those individuals observed twice. Finally, the individual variation within each group is used to investigate the interrelationships between the various aspects (form, frequency, and so on) of the stereotypic behaviour. 


\section{Incidence.}

Before the arrival of the daily meal most adult mink performed stereotypies, as shown in Table 1, with slightly fewer performing only Rigid stereotypies. In contrast, fewer than two-thirds of the adults performed stereotypies in the hours after feeding, although this number was slightly increased by the inclusion of incidental and sustained nocturnal observations of the behaviour. These incidental post-feeding observations of stereotypies were made especially in particular contexts (see below). In addition, in the adults of $1988,92.4 \%$ of the mink were observed showing some stereotypy at night, eight to ten hours after the meal, and in $15 \%$ of the mink this was sustained for more than one observation. Taking these observations into account, overall $65.7 \%$ mink in 1988 and $56.2 \%$ in 1989 performed stereotypies outside the pre-feeding period.

The data for the kits of 1988 were similar (see Table 2), with most animals performing pre-feeding stereotypies. However, many fewer kits performed stereotypies in 1990. This difference between study-sites was significant, both for pre-feeding stereotypies (females: $\chi^{2}=17.46$, $\mathrm{p}<0.001, \mathrm{df}=1$; males: $\chi^{2}=24.72, \mathrm{p}<0.001, \mathrm{df}=1$ ), and post-feeding stereotypies (females: $\chi^{2}=30.57, \mathrm{p}<0.001$, $\mathrm{df}=1$; males: $\chi^{2}=22.75$, $\mathrm{p}<0.001, \mathrm{df}=1)$. The kit data also reveal a slight sex difference: in 1988, there was a trend for males to be less likely than females to perform stereotypies post-feeding $\left(\chi^{2}=3.54, \mathrm{p}<0.10, \mathrm{df}=1\right)$. There were no significant differences between the incidence of stereotypic behaviour in 1988's adults and kits $\left(\chi^{2}\right.$ test).

Stereotypies were sometimes observed in particular contexts during scans, or incidentally at other times. For example, they were seen during disturbance by humans; when caged with an animal of the opposite sex, for mating; in animals making aggressive advances towards a neighbour; and in the breeding season, in females if shut out from the nestbox containing their young. Stereotypies would also sometimes be seen in males caged next to a sexually receptive females. They were seen too when the kits were disturbed. For example, incidental observations of stereotypy-like behaviour were recorded for kits as young as 10 weeks old (Mason, 1992a): brief head-twirls were seen in a few kits when moved into a new cage from their natal cage.

Thus overall, most mink performed stereotypies, and all mink with stereotypies performed them in the hours before the arrival of food. Some 
TABLE 1. The percentage of adult female mink that performed stereotypies

\begin{tabular}{lllll}
\hline Data set: & $\begin{array}{l}\text { Pre-feeding: } \\
\text { Stereotypy }\end{array}$ & $\begin{array}{l}\text { Rigid } \\
\text { stereotypy }\end{array}$ & $\begin{array}{l}\text { Post-feeding: } \\
\text { Stereotypy }\end{array}$ & $\begin{array}{l}\text { Rigid } \\
\text { stereotypy }\end{array}$ \\
\hline $\begin{array}{l}1988 \\
(\mathbf{N}=105)\end{array}$ & 97.0 & 94.4 & 60.0 & 49.5 \\
$\begin{array}{l}1989 \\
(\mathbf{N}=73)\end{array}$ & 100.0 & 94.5 & 49.3 & 49.3 \\
\hline
\end{tabular}

TABLE 2. The percentage of 6-7 month old mink kits that performed stereotypies

\begin{tabular}{llllll}
\hline Data set: & & $\begin{array}{l}\text { Pre-feeding: } \\
\text { Stereotypy }\end{array}$ & $\begin{array}{l}\text { Post-feeding: } \\
\text { Rigid } \\
\text { stereotypy }\end{array}$ & Stereotypy & $\begin{array}{l}\text { Rigid } \\
\text { stereotypy }\end{array}$ \\
\hline 1988: & $\begin{array}{l}\text { Females } \\
(\mathrm{N}=51)\end{array}$ & 98.0 & 98.0 & 72.5 & 72.5 \\
& $\begin{array}{l}\text { Males } \\
(\mathrm{N}=48)\end{array}$ & 97.9 & 97.9 & 54.2 & 54.2 \\
1990: & $\begin{array}{l}\text { Females } \\
(\mathrm{N}=44) \\
\text { Males } \\
(\mathrm{N}=51)\end{array}$ & 65.9 & 59.1 & 15.9 & - \\
\hline
\end{tabular}

of these animals also performed them after feeding, often when all was quiet on the farm, but sometimes too in response to particular disturbing stimuli.

II. General appearance.

a) Form.

Mink performed repetitive locomotor movements involving the elements (or 'unit components'; Fox, 1971) described below (Table 3).

Other movements were also seen, though far less frequently. These included: somersaulting backwards; pacing on the hind legs; performing sequences of rears using all parts of the cage unpredictably; U-shaped and 
TABLE 3. Common stereotypic elements observed in caged mink

Pace along cage wall

Vertical rear in cage corner; each rear occurred singly and in conjunction with pacing.

Circling or "twirl" of head/front half of body facing cage wall, back legs stationary; occurred in a series (in contrast to rearing).

Nod (as above, but moving up and down, in two dimensions only); occurred in a series (in contrast to rearing).

Entering and leaving nestbox repeatedly

horizontal 'snaking' movements of the head/front half of body, with the back half held stationary and the nose facing out of the cage; and drinkerchewing (i.e. gnawing the plastic tray under the drinker-nipple). One female would rear up, cling to the cage ceiling with her front paws, and crash down onto her back. Another female combined her locomotory stereotypy with a rhythmic squeaking, which, although not of the same periodicity as her body movements, seemed to be a form of vocal stereotypy.

The average mink, in each dataset, used three of the dozen or so elements seen in the population as a whole. Some individuals used only one, some used as many as seven, in one or more different stereotypic sequences. Stereotypies could involve the repetition of a single element (e.g. pacing), the repeated alternation of two elements, or repeated sequences of three or more elements (see Table 4). For example, one particular adult would repeat the following pattern of movements: twirl head around drinker - enter and leave nestbox - rear in back left corner of the cage - enter and leave nestbox - twirl head around drinker (repeat). Individuals varied widely in the complexity of their stereotypies.

A mink might have one or several different stereotypic sequences, with most animals having between two and four as can be seen in Table 5 .

To summarise these complex data, a typical mink combined three elements into two, three or four stereotypic sequences, each of which involved one or two of these elements.

Some stereotypic elements were combined for further analysis, to reduce the number of statistical tests performed and to lump behaviour 
TABLE 4. The number of elements used in each stereotypy

\begin{tabular}{llll}
\hline Dataset & $\begin{array}{l}\text { Range of number of } \\
\text { elements per } \\
\text { stereotypy, across } \\
\text { all the stereotypies } \\
\text { in the sample }\end{array}$ & $\begin{array}{l}\text { Range of individuals' } \\
\text { average numbers } \\
\text { of elements per } \\
\text { stereotypy }\end{array}$ & $\begin{array}{l}\text { Mean of individuals' } \\
\text { averages }\end{array}$ \\
\hline Adults 1988 & $1-5$ & $1-2.49$ & 1.60 \\
Adults 1989 & $1-5$ & $1-3.62$ & 1.77 \\
Kits 1988 & $1-4$ & $1-2.61$ & 1.51 \\
Kits 1990 & $1-4$ & $1-2.74$ & 1.79 \\
\hline
\end{tabular}

Data from 30 randomly selected individuals from each group; males and females are combined in the kit data.

TABLE 5. Frequency distributions to show the proportion of mink in each dataset that perform one, two, three or more different stereotypic sequences

\begin{tabular}{|c|c|c|c|c|c|c|c|}
\hline \multirow[t]{2}{*}{ Dataset: } & \multicolumn{7}{|c|}{ Number of stereotypic sequences in mink's repertoire: } \\
\hline & 1 & 2 & 3 & 4 & 5 & 6 & 7 \\
\hline Adults 1988 & $0.0 \%$ & $13.3 \%$ & $30.0 \%$ & $36.7 \%$ & $16.7 \%$ & $3.3 \%$ & $0.0 \%$ \\
\hline Adults 1989 & $10.0 \%$ & $36.7 \%$ & $20.0 \%$ & $23.3 \%$ & $3.3 \%$ & $3.3 \%$ & $3.3 \%$ \\
\hline Kits 1988 & $3.3 \%$ & $33.3 \%$ & $26.7 \%$ & $16.7 \%$ & $13.3 \%$ & $6.6 \%$ & $0.0 \%$ \\
\hline Kits 1990 & $13.3 \%$ & $30.0 \%$ & $23.3 \%$ & $26.7 \%$ & $3.3 \%$ & $0.0 \%$ & $3.3 \%$ \\
\hline
\end{tabular}

Data from 30 randomly selected individuals from each group; males and females are combined in the kit data.

patterns whose differences seemed to be trivial. All movements involving the length of the cage, i.e. pacing and its variants, were combined into a category called Longitudinal. This was on the grounds that they appeared, subjectively, to be a natural group, with mink slipping easily between simple pacing and forms involving rearing. Also, pacing sometimes involved very small raises of the head, in a movement intermediate between 'Pace' and 'Pace-and-rear'. Nodding, head-twirling, snaking and U-shaped movements, in which the hindlegs stayed on one spot and the mink faced the cage wall, were combined into a category called Stationary. This was because all the movements did not involve locomotion; from certain viewing angles it was difficult to distinguish reliably between nodding and twirling movements; and because some mink seemed to slip between these movements, even during a single observation. 
The proportion of stereotypy devoted to particular movements was calculated for each mink and the average values are shown in Table 6 . (The proportions shown sum to more than $100 \%$ as more than one element could be recorded during each observation, e.g. if a mink always both paced and used the nestbox, both Longitudinal and Nestbox elements would each be recorded in $100 \%$ of observations). The ranges show that there was a great deal of individual variation in the use of different forms of stereotypy. However, most individuals seemed to favour particular movements. For example, amongst the adult mink that used Longitudinal or Stationary movements, most used these patterns in the bulk of their stereotypies (see Figs. 1a \& 1b). A somewhat similar pattern can be seen in the kits (see Figs. $2 \mathrm{a} \& 2 \mathrm{~b}$ ).

The data in Table 6 reveal age-, sex-, and site-differences in the elements most commonly displayed. Comparing 1988's adult and kit females gave the following results: kits used fewer Longitudinal movements in their stereotypies (Mann-Whitney $\mathrm{U}=1266, \mathrm{p}<0.0001$ ), and made less use of the nestbox $(\mathbf{U}=1435.5, \mathrm{p}<0.0001)$, but performed Stationary elements to a greater extent $(U=1475, p<0.0001)$. The sexes did not differ significantly in their use of Longitudinal or Stationary elements, but females made the greatest use of the nestbox (1988: $\mathrm{U}=$ $851, \mathrm{p}<0.01 ; 1990$ : $\mathrm{U}=88, \mathrm{p}<0.05)$. The typical form of the animal's stereotypies also differed between the kits of 1988 and 1990, i.e. between

TABLE 6. The proportion of mink stereotypy involving particular stereotypic movements

\begin{tabular}{lcccccc}
\hline & \multicolumn{2}{c}{ Adult females } & \multicolumn{4}{c}{ Kits $(6-7$ months old $)$} \\
$\begin{array}{l}\text { \% stereotypy } \\
\text { involving: }\end{array}$ & $\begin{array}{l}1988 \\
(\mathrm{~N}=98)\end{array}$ & $\begin{array}{c}1989 \\
(\mathrm{~N}=69)\end{array}$ & \multicolumn{2}{c}{1988} & \multicolumn{2}{c}{1990} \\
& & & $\begin{array}{c}\text { Female } \\
(\mathrm{N}=50)\end{array}$ & $\begin{array}{c}\text { Male } \\
(\mathrm{N}=44)\end{array}$ & $\begin{array}{c}\text { Female } \\
(\mathrm{N}=20)\end{array}$ & $\begin{array}{c}\text { Male } \\
(\mathrm{N}=14)\end{array}$ \\
\hline $\begin{array}{l}\text { Stationary } \\
\text { elements }\end{array}$ & 39.0 & 30.2 & 64.8 & 57.0 & 37.6 & 36.7 \\
$\begin{array}{l}\text { Longitudinal } \\
\text { movements }\end{array}$ & $(0-100)$ & $(0-100)$ & $(0-100)$ & $(0-100)$ & $(0=92.3)$ & $(0-100)$ \\
the Nestbox & 14.0 & 69.0 & 33.3 & 38.8 & 61.9 & 63.3 \\
& $(0-99.0)$ & $(0-100)$ & $(0-100)$ & $(0-97.8)$ & $(9.1-100)$ & $(0-100)$ \\
\hline Ranges are & $(0-100)$ & $(0-13,0)$ & $(0-5.6)$ & $(0-94.0)$ & $(0-10.0)$ \\
\hline
\end{tabular}

Ranges are given in parentheses. 

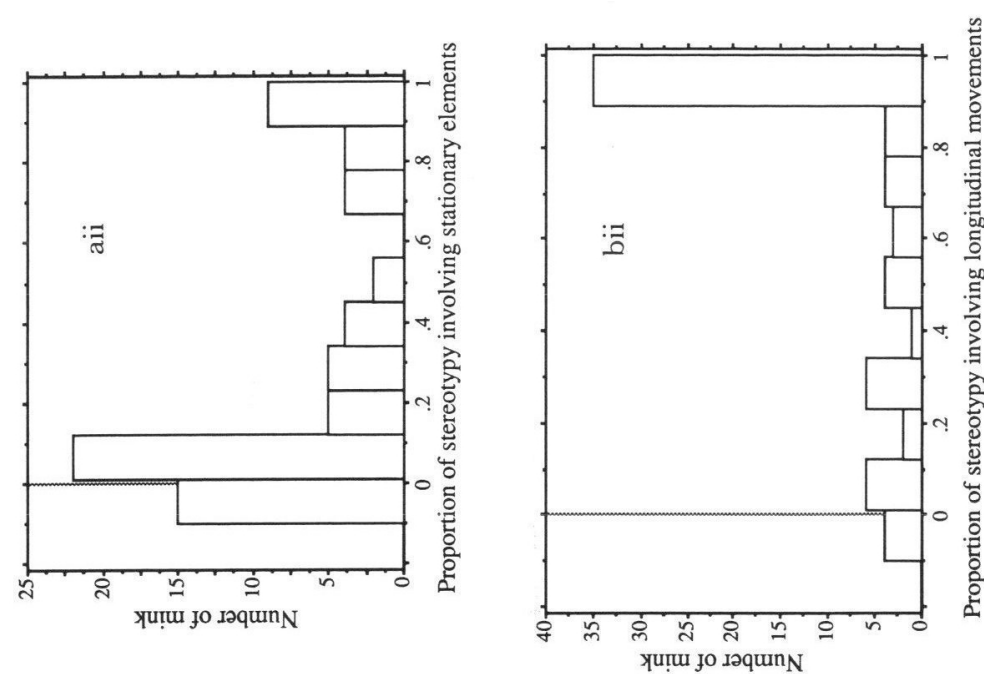

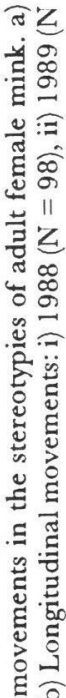

xuruu jo ıəquin $\mathrm{N}$
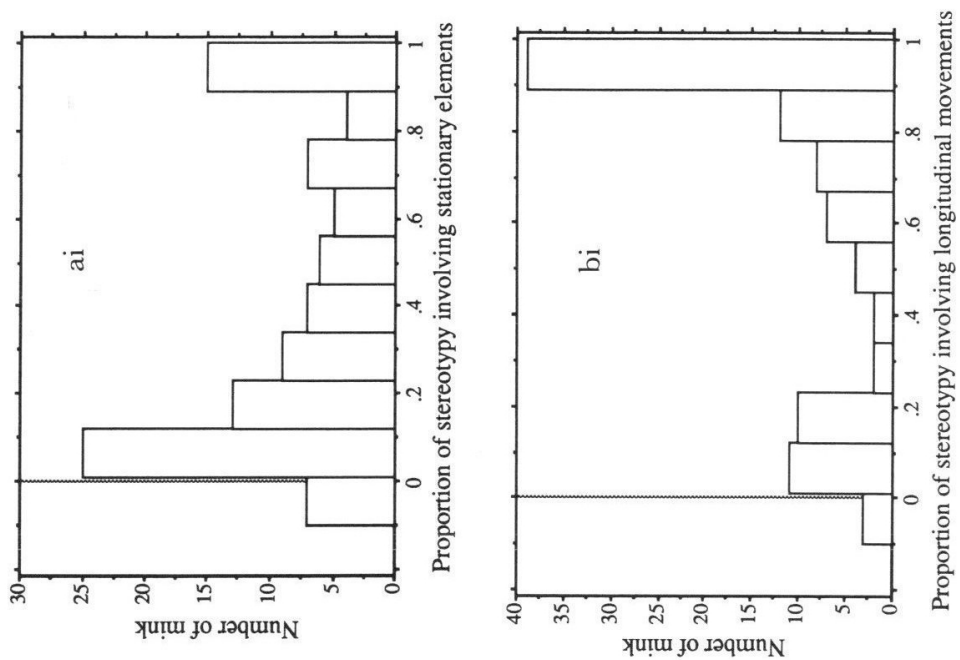

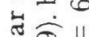

촐을

른

光

tᄂ)

高:

के

两

量资

$\left(\begin{array}{lll}\infty \\ \hdashline\end{array}\right.$

은

竞:

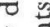

过

랑

离

- 

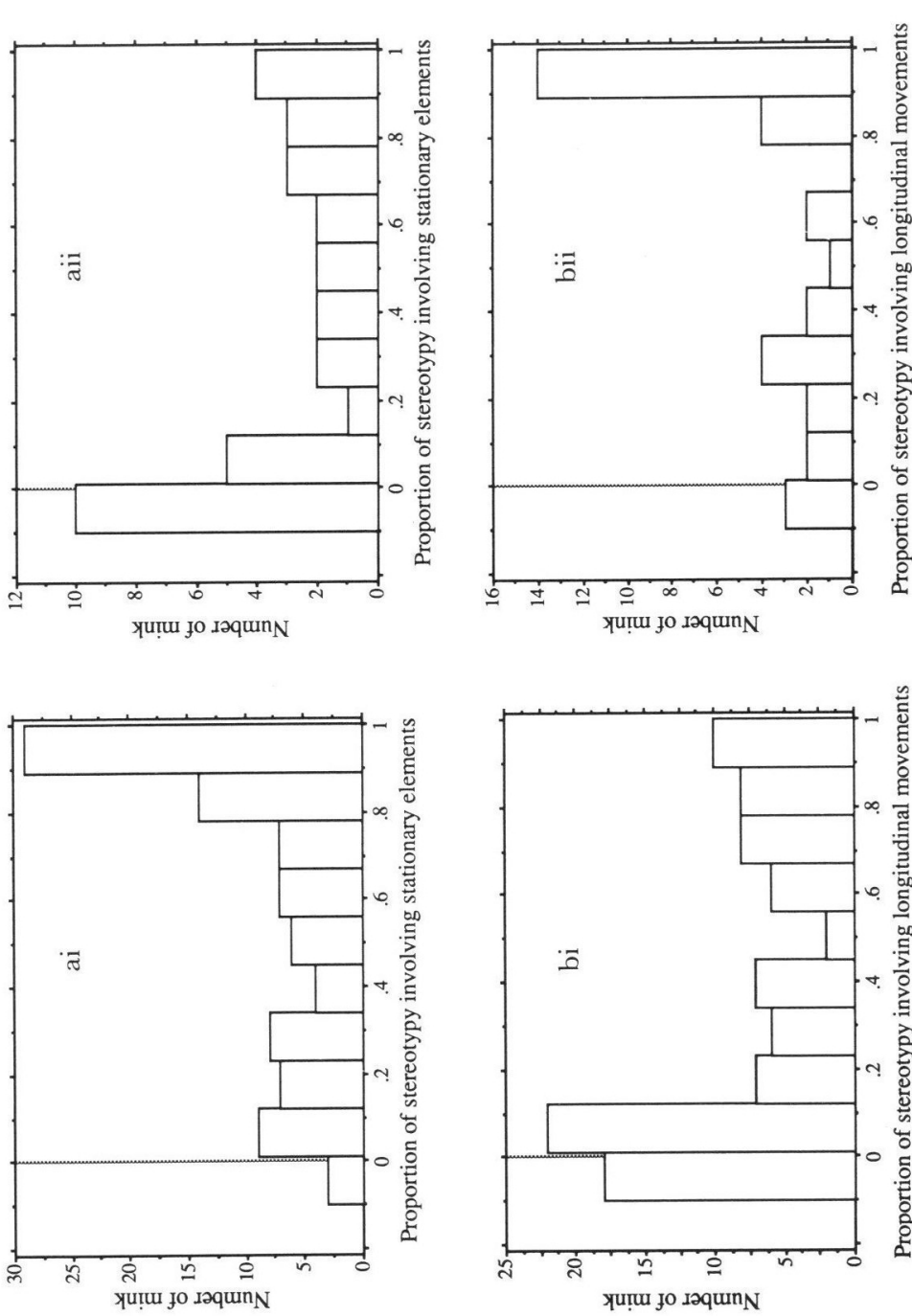

晃 $\infty \hat{\sigma}$

U $=11$ 
the two sites. Stationary movements made up a greater proportion of stereotypy in 1988 (females: $U=259, p<0.01$; males: $U=213, p<0.10$ ), while Longitudinal movements were more prevalent in 1990 (females: U $=240, p<0.001$; males: $U=194, p<0.05)$, as was the use of the nestbox, amongst the females $(\mathbf{U}=359, \mathrm{p}<0.05)$.

\section{b) Variability.}

The results of assessing the variability of mink stereotypies are presented in Table 7. Individuals varied within, and also between, groups. The data reveal age- and site-differences, although no significant sex differences. Comparing the adult and kit females of 1988 showed that adult stereotypies were less variable according to the Stereotypy/Restless behaviour score (Mann-Whitney $\mathrm{U}=2072.5, \mathrm{p}<0.05$ ), although their Rigidity Indices did not differ significantly. Site differences were as follows: female kits in 1988 had higher Rigidity Indices $(U=406, p<0.01)$ and Stereotypy/Restless behaviour scores $(\mathbf{U}=602.5, \mathrm{p}<0.05)$ than those studied on the Dutch site. Male kits showed no such site differences, however.

Some qualitative impressions were gained of variation in the location, speed and precise timing of mink stereotypies. These attributes could vary even when the form of the sequence was predictable. In all the groups, the part of the cage used was influenced by the feeding machine, the mink orientating towards it as it drew near. When not feeder-related, the sidepreference might be determined by the position of a neighbouring animal, mink sometimes even following each other and mirroring each

TABLE 7. The results of assessing the variability of stereotypic behaviour in mink

\begin{tabular}{|c|c|c|c|c|c|c|}
\hline \multirow{3}{*}{$\begin{array}{l}\text { Assessment of } \\
\text { variability }\end{array}$} & \multicolumn{2}{|c|}{ Adult females } & \multicolumn{4}{|c|}{ Kits (6-7 months old) } \\
\hline & \multirow[t]{2}{*}{1988} & \multirow[t]{2}{*}{1989} & \multicolumn{2}{|c|}{1988} & \multicolumn{2}{|c|}{1990} \\
\hline & & & Female & Male & Female & Male \\
\hline $\begin{array}{l}\text { Rigidity Index } \\
\text { (Rigid stereotypy/ } \\
\text { Stereotypy) }\end{array}$ & $\begin{array}{c}0.76 \pm 0.19 \\
(N=99)\end{array}$ & $\begin{array}{c}0.69 \pm 0.22 \\
(\mathbf{N}=69)\end{array}$ & $\begin{array}{c}0.76 \pm 0.21 \\
(\mathrm{~N}=50)\end{array}$ & $\begin{array}{l}0.74 \pm 0.17 \\
(\mathrm{~N}=43)\end{array}$ & $\begin{array}{l}0.58 \pm 0.26 \\
(\mathrm{~N}=26)\end{array}$ & $\begin{array}{c}0.66 \pm 0.25 \\
(\mathrm{~N}=23)\end{array}$ \\
\hline $\begin{array}{l}\text { Stereotypy/ } \\
\text { Restless behaviour }\end{array}$ & $\begin{array}{c}0.90 \pm 0.16 \\
(\mathrm{~N}=98)\end{array}$ & $\begin{array}{c}0.97 \pm 0.09 \\
(\mathrm{~N}=73)\end{array}$ & $\begin{array}{l}0.97 \pm 0.06 \\
(\mathrm{~N}=50)\end{array}$ & $\begin{array}{l}0.95 \pm 0.09 \\
(\mathrm{~N}=47)\end{array}$ & $\begin{array}{l}0.78 \pm 0.35 \\
(\mathrm{~N}=33)\end{array}$ & $\begin{array}{c}0.84 \pm 0.27 \\
(\mathrm{~N}=30)\end{array}$ \\
\hline
\end{tabular}


others' stereotypies. Incidental observations made during the mating season showed stereotypies also to be influenced by animals of the opposite sex. Five of the six adult females observed stereotyping when caged with a male did so as far from the male as possible; while 16/16 males observed stereotyping when caged next to a potentially receptive female performed the behaviour on the side of the cage nearest her. In all groups of mink, stereotypies seemed to be performed at particularly high speeds just before feeding (sometimes accompanied by squeaking calls), while in the hours after feeding they seemed to be performed at a gentler pace. Incredible synchronization of movement was shown by the kits of the 1988 dataset, who unlike 1990's kits were housed in male-female pairs. They often performed stereotypies that meshed with the behaviour of their cagemates, such that both animals might be running up and down the cage at high speed, crossing midway, one mink passing over the other, yet never colliding.

\section{Frequency.}

The mean levels of stereotypy pre- and post-feeding are presented in Tables $8 \mathrm{a} \& \mathrm{~b}$. In the hours before feeding, adult mink spent approximately half their time performing stereotypies, kits somewhat less, especially on the Dutch farm. There was considerable individual variation in the amount of time this involved (see ranges in Table 8 a \& b).

Stereotypy levels were significantly higher pre-feeding than post-feeding in all groups (see Wilcoxon test results in Tables $8 \mathrm{a} \& 8 \mathrm{~b}$ ). During the pre-feeding period, stereotypy levels rose as feeding time approached. For example, in 1988, the stereotypy level of the average adult female rose over the six hours pre-feeding from around $20 \%$ observations to around $60 \%$ (see Fig. 3). In these adults, animals were sometimes observed performing stereotypies as early as seven or eight hours before feeding. After feeding, stereotypy then decreased to a very low level. All the groups observed followed a similar diurnal pattern. A similar morning rise in the stereotypies of 1988's adults occurred on a day when no animals were fed anywhere on the farm (Fig. 4), though note that stereotypies then remained relatively high throughout the day.

When 1988's adult and kit females were compared, adults had the highest levels of stereotypy pre-feeding (Mann-Whitney $\mathrm{U}=1245.5$, $\mathrm{p}<0.0001)$, and post-feeding $(\mathrm{U}=2148, \mathrm{p}<0.05)$. Female kits also showed 
TABLE 8A. The frequency of stereotypy of the average adult female mink

\begin{tabular}{lcccc}
\hline Dataset: & \multicolumn{2}{c}{$\begin{array}{c}\text { \%observations pre-feeding } \\
\text { spent in: }\end{array}$} & $\begin{array}{c}\% \text { observations post-feeding } \\
\text { spent in: }\end{array}$ \\
& Stereotypy & $\begin{array}{c}\text { Rigid } \\
\text { stereotypy }\end{array}$ & Stereotypy & $\begin{array}{c}\text { Rigid } \\
\text { stereotypy }\end{array}$ \\
\hline 1988 & $48.1 \pm 18.6 \mathrm{a}$ & $37.1 \pm 18.0$ & $2.0 \mathrm{a}$ & 1.5 \\
$(\mathbf{N}=105)$ & $(0-78.2)$ & $(0-55.8)$ & $(0-18.3)$ & $(0-16.1)$ \\
1989 & $50.0 \pm 20.2 \mathrm{~b}$ & $37.0 \pm 17.0$ & $1.1 \pm 2.0 \mathrm{~b}$ & 1.0 \\
$(\mathbf{N}=73)$ & $(0.6-80.0)$ & $(0-60.3)$ & $(0-10.9)$ & $(0-7.8)$ \\
\hline
\end{tabular}

Ranges are given in parentheses.

a) Wilcoxon $Z=8.85, \mathrm{p}<0.0001$.

b) Wilcoxon $Z=7.42, p<0.0001$.

TABLE 8B. The frequency of stereotypy in the average 6-7 month old mink kit

\begin{tabular}{|c|c|c|c|c|}
\hline \multirow[t]{2}{*}{ Dataset: } & \multicolumn{2}{|c|}{$\begin{array}{l}\% \text { observations pre-feeding } \\
\text { spent in: }\end{array}$} & \multicolumn{2}{|c|}{$\begin{array}{l}\% \text { observations post- } \\
\text { feeding } \\
\text { spent in: }\end{array}$} \\
\hline & Stereotypy & $\begin{array}{l}\text { Rigid } \\
\text { stereotypy }\end{array}$ & Stereotypy & $\begin{array}{l}\text { Rigid } \\
\text { stereotypy }\end{array}$ \\
\hline \multicolumn{5}{|l|}{ 1988: } \\
\hline $\begin{array}{l}\text { Female } \\
(\mathrm{N}=51)\end{array}$ & $\begin{array}{c}30.8 \pm 17.0{ }^{a} \\
(0-66.9)\end{array}$ & $\begin{array}{l}23.5 \pm 13.6 \\
(0-57.1)\end{array}$ & $\begin{array}{c}2.3^{\mathrm{a}} \\
(0-20.9)\end{array}$ & $\begin{array}{c}2.1 \\
(0-19.1)\end{array}$ \\
\hline $\begin{array}{l}\text { Male } \\
(\mathrm{N}=48)\end{array}$ & $\begin{array}{c}20.4 \pm 13.6 \mathrm{~b} \\
(0-54.5)\end{array}$ & $\begin{array}{c}16.9 \pm 11.1 \\
(0-44.1)\end{array}$ & $\begin{array}{c}1.0 \mathrm{~b} \\
(0-8.9)\end{array}$ & $\begin{array}{c}0.8 \\
(0-\quad 5.0)\end{array}$ \\
\hline \multicolumn{5}{|l|}{ 1990: } \\
\hline $\begin{array}{l}\text { Female } \\
(\mathrm{N}=44)\end{array}$ & $\begin{array}{c}14.4 \\
(0-72.2)\end{array}$ & $\begin{array}{c}12.1 \\
(0-49.2)\end{array}$ & No data & No data \\
\hline $\begin{array}{l}\text { Male } \\
(\mathrm{N}=51)\end{array}$ & $\begin{array}{c}5.3 \\
(0-37.3)\end{array}$ & $\begin{array}{c}3.6 \\
(0-34.2)\end{array}$ & No data & No data \\
\hline
\end{tabular}

a) Wilcoxon $Z=6.03, \mathrm{p}<0.0001$.

b) Wilcoxon $Z=6.02, p<0.0001$.

higher stereotypy levels than male kits: in 1988, stereotypy levels prefeeding (Unpaired $\mathrm{T}$ test: $\mathrm{t}=3.35, \mathrm{df}=97, \mathrm{p}<0.01$ ) and post-feeding $(\mathrm{U}=$ 809.5, $\mathrm{p}<0.01$ ) were higher in females, and in 1990 this was a trend for stereotypy pre-feeding $(\mathrm{p}<0.10)$, but significant for Rigid stereotypy prefeeding $\left.(\mathbf{U}=820.5, \mathrm{p}<0.05) .{ }^{2}\right)$

2) This sex difference was also found in adults; analysis of unpublished data collected by G. DE JoNGE showed females $(N=16)$ to spend more time in stereotypy than males $(N=24)(U=98$, $\mathrm{p}<0.01$ ). 

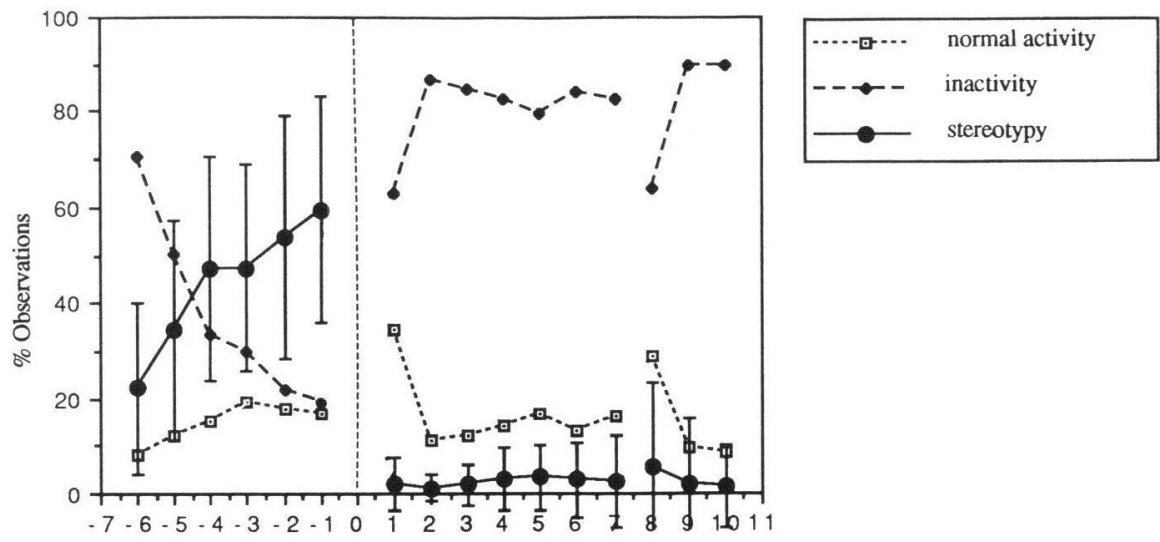

Hours before/after feeding

Fig. 3. The diurnal activity of caged adult female mink (Data are means of 105 animals' average activity levels over 14 days in late March/early April 1988).
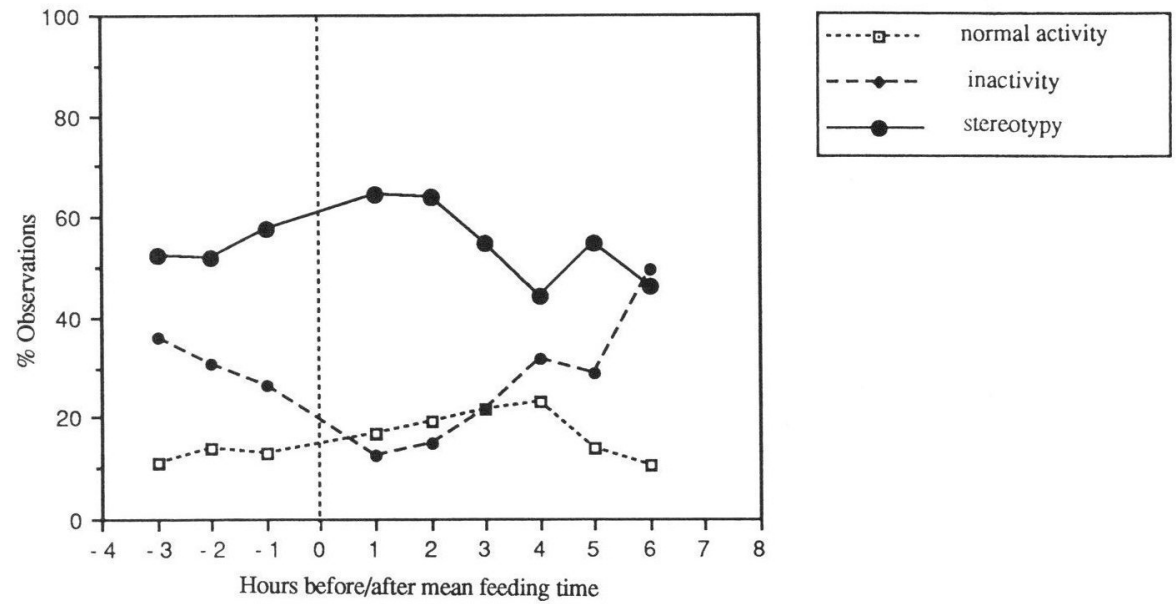

Fig. 4. The diurnal activity of caged adult female mink on a day when not fed (Data are means of 105 animals' activity levels).

The kits also revealed site differences, with the animals of the UK site having the highest levels of pre-feeding stereotypy (females: $U=502.5$, $\mathrm{p}<0.0001$; males: $\mathrm{U}=347.5, \mathrm{p}<0.0001$ ). This difference remained significant when kits with no stereotypy at all were excluded. 
IV. Effects of age - additional data.

a) Adult age and stereotypy - comparisons within each group.

Hardly any differences were found between the primiparous and multiparous females. There were no significant differences in their stereotypy's form, nor in the proportion of animals with stereotypy post-feeding. The one difference in frequency was that in 1989, primiparous females ( $\mathrm{N}=$ 57) had lower levels of Rigid stereotypy pre-feeding than the older mink $(\mathrm{N}=49$ ) (Unpaired $\mathrm{T}$ test: $\mathrm{t}=2.06, \mathrm{p}<0.05$; mean for primipares $=$ $37.1 \pm 16.0 \%$; mean for multipares $=43.0 \pm 15.9 \%$ ).

\section{b) Longitudinal studies over time.}

i) Kits at six and ten months of age.

In mink observed as kits in November 1988 and then as young adults in March 1989, there was a trend for stereotypy levels pre-feeding to correlate positively at the different ages (see Fig. 5; correlation coefficient $=$ $0.48, \mathrm{~N}=15, \mathrm{p}<0.10$ ). There was also an increase in the mean frequency of the behaviour, from $30.1 \%$ to $56.7 \%$ (Wilcoxon $Z=3.35, \mathrm{p}<0.001$ ). There were clear positive correlations between the proportion of stereotypy devoted to particular movements, from one age to the next: for $\%$ stereotypy involving Stationary elements, Spearman rank correlation = $0.78, \mathrm{p}<0.01, \mathrm{~N}=14$; and for \% stereotypy involving Longitudinal movements, Spearman rank correlation $=0.59, \mathrm{p}<0.05, \mathrm{~N}=14$. How-

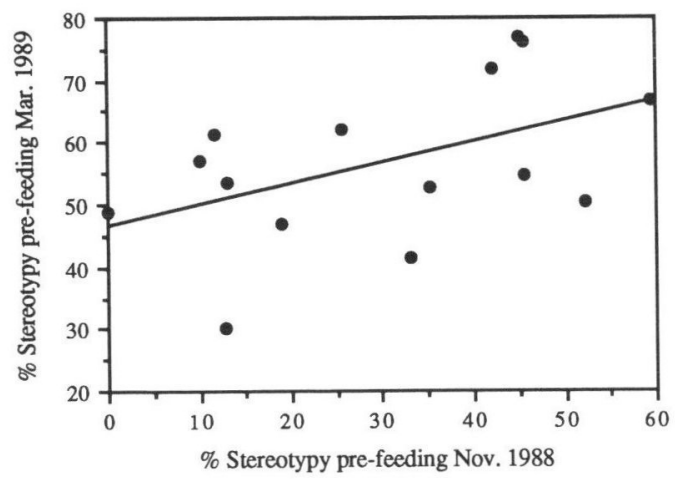

Fig. 5. The pre-feeding stereotypy levels of 6-month old female kits in November 1988, and four months later in March 1989: $\mathrm{R}=0.48, \mathrm{p}<0.10(\mathrm{~N}=15)$. 
ever, the incidence of these different movements did change over this period. The relative use of Stationary elements decreased (Wilcoxon $Z=$ $2.17, N=14, p<0.05)$, while the use of the nestbox $(Z=2.41, p<0.05)$ and the use of Longitudinal movements $(Z=92.1, p<0.05)$ increased.

Rigidity Indices did not correlate over this period, but Stereotypy/ Restless scores did (Spearman rank correlation $=0.56, \mathrm{~N}=14, \mathrm{p}<0.05$ ). Stereotypy/Restless scores, although again not Rigidity Indices, also changed over this period, increasing from 0.95 to $0.99(\mathrm{Z}=2.85, \mathrm{p}<0.01)$. The proportion of mink with stereotypy post-feeding did not change over this period $\left(\chi^{2}\right.$ test $)$.

\section{ii) Longitudinal studies of adults.}

For the 1988 adults re-watched in 1989, there was a strong correlation between 1988 and 1989 levels of pre-feeding stereotypy (see Fig. 6; correlation coefficient $=0.86, \mathrm{~N}=41, \mathrm{p}<0.001)$. The proportion of stereotypy made up of different forms also correlated from one year to the next (see Figs 7 a - c for Spearman rank correlation coefficients), as did Rigidity Indices (Spearman rank correlation $=0.59, \mathrm{~N}=37, \mathrm{p}<0.001$ ), although Stereotypy/Restless behaviour scores did not.

However, once again, the proportions of the different types of stereotypy did not stay constant. Over the twelve month period, the proportion of stereotypies involving Stationary movements declined (Wilcoxon $\mathrm{Z}=$ $2.09, \mathrm{p}<0.05)$, as did the use of the nestbox during stereotypy $(Z=4.03$,

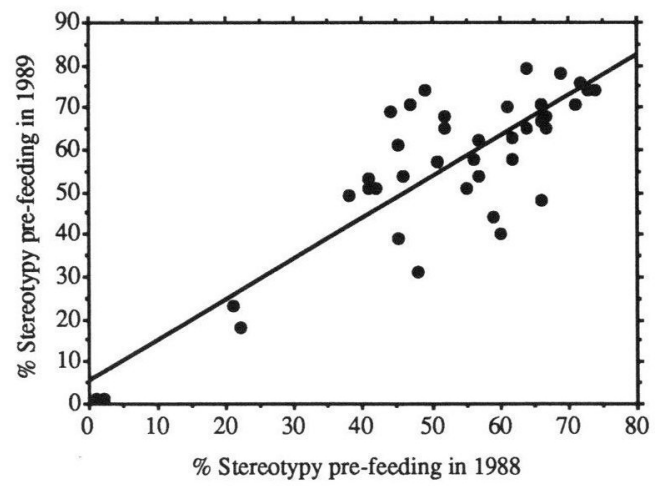

Fig. 6. The pre-feeding stereotypy levels of adult female mink in 1988 and 12 months later: $\mathrm{R}=0.86, \mathrm{p}<0.001(\mathrm{~N}=41)$. 


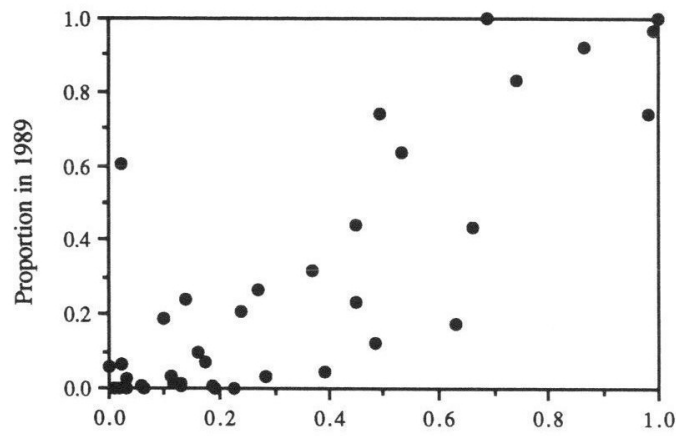

Proportion of stereotypy involving Stationary elements in 1988

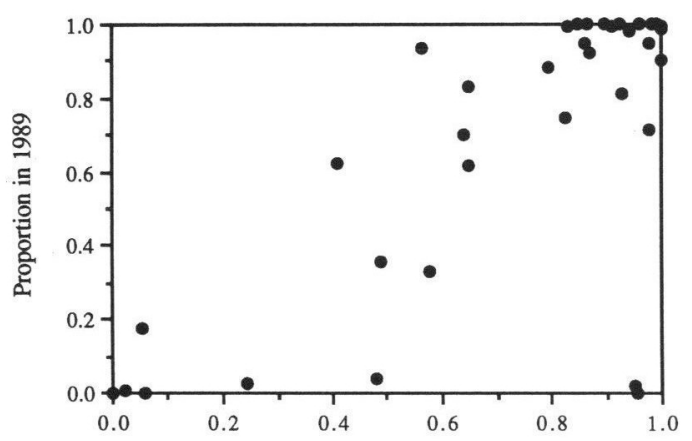

Proportion of stereotypy involving Longitudinal movements in 1988

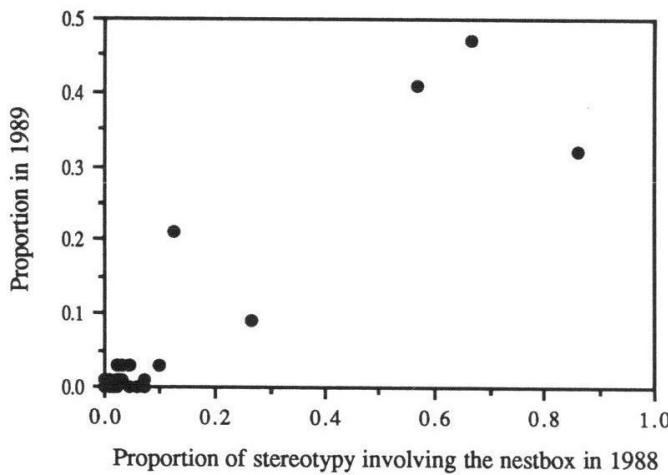

Fig. 7. The forms of stereotypy in adult female mink in 1988 and 12 months later: a) Stationary elements. Spearman rank correlation $=0.73, \mathrm{p}<0.000 \mathrm{l}(\mathrm{N}=38)$. b) Longitudinal movements. Spearman rank correlation $=0.60, p<0.001(\mathrm{~N}=37)$. c) Using the nestbox. Spearman rank correlation $=0.67, \mathrm{p}<0.0001(\mathrm{~N}=39)$. 
$\mathrm{p}<0.0001)$. There was no significant change in the use of Longitudinal movements, however. Over this period, Rigidity Indices did not increase, but Stereotypy/Restless behaviour scores $\operatorname{did}(Z=3.6, p<0.001)$. The proportion of animals with stereotypies restricted to the pre-feeding period did not change $\left(\chi^{2}\right.$ test).

Of 1988's adults that were re-watched, 16 were selected as having particularly distinctive stereotypies, either because a single stereotypic sequence dominated their repertoire or because they used the unusual movement of somersaulting. Their behaviour in 1989 was then examined. The results are presented in Table 9. As can be seen, mink sometimes changed their behaviour from one Longitudinal form to another, or from one Stationary form to another, but otherwise their behaviour was remarkably stable.

V. Interrelations between aspects of stereotypy.

a) Frequency, variability and context.

The relationship between the levels of stereotypy pre- and post-feeding is shown in Fig. 8a \& b (for adults) and Fig. 9a \& b (for 1988's kits). As can be seen, individuals varied considerably in their levels but a mink with stereotypy always performed it in the pre-feeding period (with the single exception of one male kit in 1988). Amongst the adults, it can be seen that high levels of pre-feeding stereotypy were linked with high levels of stereotypy post-feeding. Classifying animals according to whether or not their stereotypies were performed outside the pre-feeding context revealed that adult mink performing stereotypies in more than one context had higher levels pre-feeding (see Table 10).

However, the pattern for kits did not resemble that of adults. Kits with post-feeding stereotypy did not have higher levels of pre-feeding stereotypy, in either dataset (1988: Unpaired T-test; 1990: Mann-Whitney U test). Thus adults and kits differed in how their stereotypies were distributed over the day: adults tended to show stereotypies post-feeding only if their pre-feeding levels were high; kits, however, could have relatively low levels pre-feeding with relatively high levels post-feeding. These age differences were demonstrated further by calculating the levels of postfeeding stereotypy for kits and adults in 1988 with above or below their group's median level of pre-feeding stereotypy. Amongst the adults, mink 
TABLE 9. Idiosyncratic stereotypies observed in individual adult female mink from one year to the next

\begin{tabular}{|c|c|c|}
\hline Mink & Typical stereotypy in 1988 & Typical stereotypy in 1989 \\
\hline 1 & $\begin{array}{l}\text { Pace, rearing at both ends of the } \\
\text { cage }\end{array}$ & Pace, rearing at one end of the cage \\
\hline 2 & $\begin{array}{l}\text { Pace, rearing at both ends of the } \\
\text { cage }\end{array}$ & $\begin{array}{l}\text { Pace, rearing at both ends of the } \\
\text { cage }\end{array}$ \\
\hline 3 & Pace, rearing at one end of the cage & Pace (no rearing) \\
\hline 4 & $\begin{array}{l}\text { Pace, rearing at both ends of the } \\
\text { cage }\end{array}$ & $\begin{array}{l}\text { Pace, rearing at both ends of the } \\
\text { cage }\end{array}$ \\
\hline 5 & $\begin{array}{l}\text { Snaking movement, hindlegs } \\
\text { stationary }\end{array}$ & Head-twirl, hindlegs stationary \\
\hline 6 & $\begin{array}{l}\text { Pace, with very low rear at one end } \\
\text { of the cage; very occasional head- } \\
\text { twirl or nod, hindlegs stationary }\end{array}$ & $\begin{array}{l}\text { Pace (no rearing); head-twirls, hin- } \\
\text { dlegs stationary }\end{array}$ \\
\hline 7 & Head-twirl, hindlegs stationary & Head-twirl, hindlegs stationary \\
\hline 8 & Nod, hindlegs stationary & Head-twirl, hindlegs stationary \\
\hline 9 & $\begin{array}{l}\text { Pace, rearing at both ends of the } \\
\text { cage }\end{array}$ & Pace, rearing at one end of the cage \\
\hline 10 & $\begin{array}{l}\text { Enter and leave the nestbox, inter- } \\
\text { spersed with rearing and head-twirls }\end{array}$ & $\begin{array}{l}\text { Enter and leave the nestbox, inter- } \\
\text { spersed with rearing and head-twirls }\end{array}$ \\
\hline 11 & $\begin{array}{l}\text { Pace, occasionally rearing at one end } \\
\text { of the cage }\end{array}$ & $\begin{array}{l}\text { Pace, occasionally rearing at one end } \\
\text { of the cage }\end{array}$ \\
\hline 12 & $\begin{array}{l}\text { Pace, rearing at one end of the cage; } \\
\text { very occasional somersault }\end{array}$ & $\begin{array}{l}\text { Pace, rearing at both ends of the } \\
\text { cage; somersaults }\end{array}$ \\
\hline 13 & Some somersaults & No somersaults \\
\hline 14 & Enter and leave nestbox; pace & Enter and leave nestbox; pace \\
\hline 15 & Rearing in all parts of the cage & Rearing in all parts of the cage \\
\hline 16 & Rearing in all parts of the cage & Rearing in all parts of the cage \\
\hline
\end{tabular}

with above median levels of pre-feeding stereotypy $(\mathrm{N}=79)$ had higher levels of stereotypy post-feeding than those with below median levels $(\mathrm{N}=$ 26) (mean $=2.49 \%$ post-feeding, compared to $0.58 \% ; \mathrm{U}=713.5$, $\mathrm{p}<0.05)$. However, there was no such significant difference in the kits: whether stereotypy levels were high or low pre-feeding did not predict their levels post-feeding.

The variability of stereotypies was also related to when they were performed, in the adults. Adult mink that performed stereotypies in more than one context were less variable in their movements than other mink, 

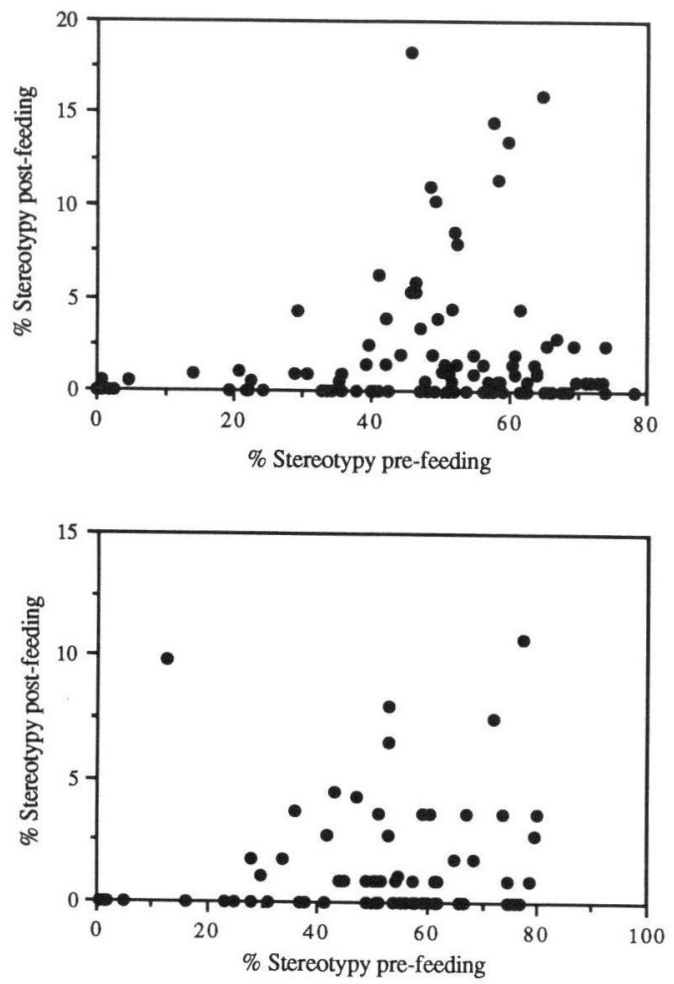

b

Fig. 8. Stereotypy levels before and after feeding in adult female mink: a) $1988(\mathrm{~N}=105)$, b) $1989(\mathrm{~N}=73)$.

in terms of Rigidity Index (see Table 10). Again, however, in kits the relationship between the timing and variability of stereotypies did not fit the adult pattern: the variability of the kits' behaviour was not decreased if the stereotypies were seen in more than one context (Unpaired T-tests: NS).

The frequency of an adult mink's stereotypy also predicted its variability, with variability decreasing with higher frequencies of the behaviour. Stereotypy levels pre-feeding correlated positively with the behaviour's Stereotypy/Restless behaviour score in 1988 (Spearman rank correlation $=0.20, \mathrm{p}<0.05, \mathrm{~N}=104$ ) and 1989 (Spearman rank correlation $=0.30, \mathrm{p}<0.05, \mathrm{~N}=73$ ), and with its Rigidity Index in 1988 (Spearman rank correlation $=0.29, \mathrm{p}<0.01, \mathrm{~N}=99 ; 1989-\mathrm{NS})$. This relationship between frequency and variability of stereotypies was absent in the kits, however. There were no significant relationships in 1988's kit 

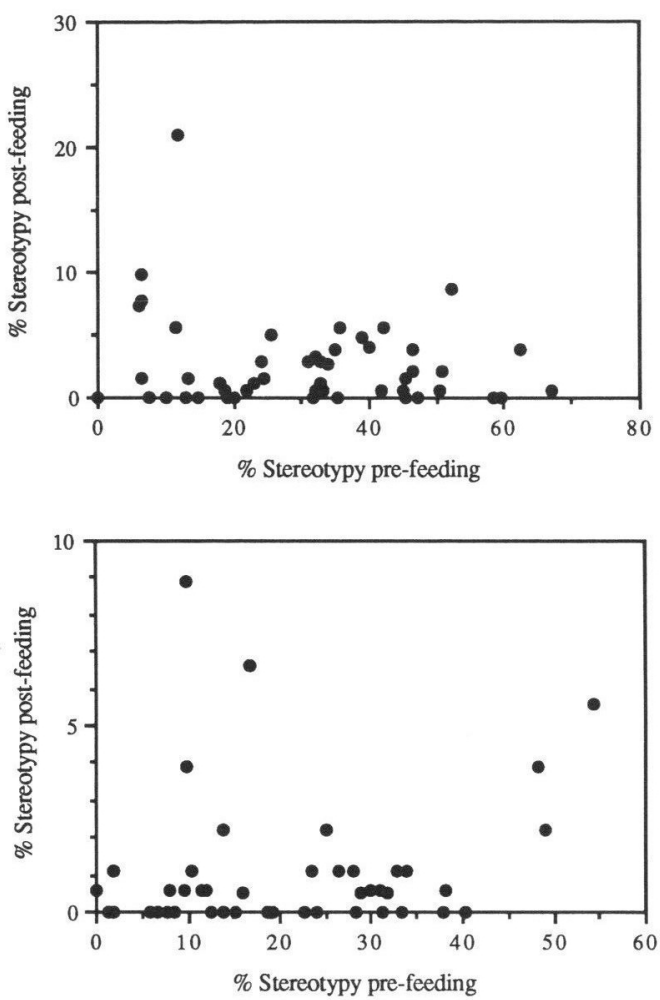

Fig. 9. Stereotypy levels before and after feeding in 6-7 month old mink kits (1988): a) Females $(\mathrm{N}=51)$, b) Males $(\mathrm{N}=48)$.

data, nor in the data of 1990's males. Indeed, in 1990's females prefeeding stereotypy levels and Rigidity Indices unexpectedly correlated negatively (Spearman rank correlation $=-0.39, \mathrm{p}<0.05, \mathrm{~N}=26$ ), although pre-feeding stereotypy levels and the Stereotypy/Restless behaviour score positively correlated in these same animals (Spearman rank correlation $=$ $0.39, \mathrm{p}<0.05, \mathrm{~N}=33$ ).

\section{b) Form and context.}

In addition to variability, the forms of stereotypy used by different individuals could also be predicted from the contexts in which the behaviour was performed.

In the adults of 1988, animals which did or did not show stereotypies outside the pre-feeding situation had different preferred movements. If a 
TABLe 10. A comparison of the stereotypy levels and Rigidity Indices of adult mink with stereotypies pre-feeding only, and with stereotypies also performed in other contexts

\begin{tabular}{|c|c|c|c|c|}
\hline $\begin{array}{l}\text { Aspect of } \\
\text { stereotypy: }\end{array}$ & Data set: & $\begin{array}{c}\text { Mink with } \\
\text { stereotypies } \\
\text { pre-feeding only }\end{array}$ & $\begin{array}{c}\text { Mink with } \\
\text { stereotypies also } \\
\text { seen outside } \\
\text { pre-feeding period }\end{array}$ & T-test results \\
\hline \multirow{2}{*}{$\begin{array}{l}\text { Stereotypy } \\
\text { frequency, } \\
\text { pre-feeding }\end{array}$} & 1988 & $\begin{array}{c}42.61 \pm 22.75 \\
(\mathrm{~N}=36)\end{array}$ & $\begin{array}{c}50.94 \pm 15.39 \\
(\mathbf{N}=69)\end{array}$ & $\mathrm{t}=2.22, \mathrm{p}<0.05$ \\
\hline & 1989 & $\begin{array}{c}45.29 \pm 23.17 \\
(\mathrm{~N}=31)\end{array}$ & $\begin{array}{c}54.48 \pm 17.12 \\
(\mathrm{~N}=42)\end{array}$ & $\mathrm{t}=1.74, \mathrm{p}<0.10$ \\
\hline \multirow{2}{*}{$\begin{array}{l}\text { Rigid } \\
\text { stereotypy } \\
\text { frequency, } \\
\text { prefeeding }\end{array}$} & 1988 & $\begin{array}{c}30.18 \pm 19.62 \\
(\mathrm{~N}=36)\end{array}$ & $\begin{array}{c}40.75 \pm 16.11 \\
(\mathrm{~N}=69)\end{array}$ & $\mathrm{t}=2.96, \mathrm{p}<0.01$ \\
\hline & 1989 & $\begin{array}{c}32.06 \pm 18.91 \\
(\mathrm{~N}=28)\end{array}$ & $\begin{array}{c}40.52 \pm 14.11 \\
(\mathrm{~N}=41)\end{array}$ & $\mathrm{t}=2.13, \mathrm{p}<0.05$ \\
\hline \multirow[t]{2}{*}{ Rigidity Index } & 1988 & $\begin{array}{c}0.70 \pm 0.21 \\
(\mathrm{~N}=31)\end{array}$ & $\begin{array}{c}0.80 \pm 0.22 \\
(\mathrm{~N}=68)\end{array}$ & $\mathrm{t}=2.28, \mathrm{p}<0.05$ \\
\hline & 1989 & $\begin{array}{c}0.61 \pm 0.23 \\
(\mathbf{N}=28)\end{array}$ & $\begin{array}{c}0.75 \pm 0.19 \\
(\mathbf{N}=41)\end{array}$ & $\mathrm{t}=2.72, \mathrm{p}<0.01$ \\
\hline
\end{tabular}

mink's stereotypies were restricted to the pre-feeding period, the majority of its stereotypies was more likely to involve Longitudinal movements $\left(\chi^{2}\right.$ $=11.65, \mathrm{p}<0.001)$. Conversely, if an individual performed stereotypies in more than this one context, more than half of its behaviour tended to involve Stationary elements $\left(\chi^{2}=5.15, \mathrm{p}<0.05\right)$. Similar results emerged when the 'extremes' evident in Fig. 8a were compared. 'Stereotypy high pre-feeding, low post-feeding' mink $(\mathrm{N}=15)$ used a greater proportion of Longitudinal movements (Mann-Whitney $\mathrm{U}=44, \mathrm{p}<0.05$ ) and a smaller proportion of Stationary elements $(\mathbf{U}=37, \mathrm{p}<0.01)$ than the 'Stereotypy high pre-feeding, high post-feeding' mink ( $N=13)$.

Comparing stereotypies pre-feeding with those performed post-feeding showed no significant difference in the proportion of stereotypies made up of Longitudinal movements before and after feeding (Wilcoxon test), but there was a trend for Stationary elements to make up a greater proportion of stereotypies after feeding than before $(Z=1.95, p=0.055)$, while using the nextbox was seen during more of the stereotypies before feeding $(Z=3.17, p<0.01)$. However, these results were not replicated in 1989. 
To see if stereotypies changed in form during the pre-feeding period, individuals who generally started the behaviour early in the day were selected from each dataset, and stereotypy early in the day (i.e. over three hours to over six hours before the arrival of food, depending on the group) was compared to the same individual's stereotypy in the last hour before food. There were no significant results for the 1988 adults $(\mathrm{N}=30)$, but in the 1989 adults $(\mathrm{N}=19)$, the use of the nestbox increased as feeding time approached $(\mathrm{Z}=2.55, \mathrm{p}<0.05)$.

Amongst the kits, the only significant associations between context and form were as follows. In 1988's kits, Stationary elements occurred in a greater proportion of stereotypies post-feeding than pre-feeding (Sign Test: $N=17, x=3, p<0.05$; sexes were combined because of small sample sizes). Longitiudinal movements did not differ in relative frequency before or after feeding, as in the adults. The following difference was found between stereotypy early in the day and that performed just before feeding: in the kits of $1988(\mathrm{~N}=17)$, Stationary elements were found in fewer stereotypies as feeding approached $(Z=2.41, p<0.05)$. No differences were found in the kits of $1990(\mathrm{~N}=16)$.

Thus overall, although similar movements were seen pre- and postfeeding, Stationary elements seemed least prevalent as the arrival of food approached and most prevalent post-feeding, while the converse was true for running in and out of the nestbox. Longitudinal movements were also associated with the pre-feeding context, in one dataset.

\section{Discussion}

Introduction.

Mink stereotypies involved certain movements that recurred again and again across the populations studied. Stationary elements and Longitudinal movements were the most common forms on both sites, as they have been found to be in a Danish population (Hansen, in press). However, some individuals also developed uncommon, idiosyncratic movements such as somersaulting. The combination of individual differences and species-typical morphologies resembles that found for the stereotypies of stall-housed sows (CRONin et al., 1984). Although some differences may be trivial (such as whether a mink rears at one or at both ends of a cage), the 
variation in form does suggest that mink stereotypies may be heterogeneous in causation.

The mink also differed in the complexity of their stereotypies, and the number of different movements that they employed. Some performed a single repeated element or sequence, but most performed more than one type of sequence. This confirms the findings of Hansen (in press), and conflicts with DE JONGE et al. (1986)'s statement that 'if [a mink] has one stereotypy, we do not see a second'. There was no evidence, however, that sequences involved greater numbers of elements with age, as has been reported in sows (Cronin et al., 1984). Individual mink also differed in the variability of their stereotypies, and again this resembles the type of individual variation recorded in pigs (e.g. Cronin \& Wiepkema, 1984). Individual differences in variability may be influenced by individual differences in the ease with which behaviour becomes routine-like (MAson, 1991b). However, the variability of the behaviour also depended on its age and degree of 'establishment', as discussed below.

Development of mink stereotypy.

Developmental data came from comparing 1988's adult and kit females, the primiparous and multiparous females within each adult dataset, kit behaviour in the autumn of 1988 with their behaviour in the spring of 1989, and adults observed in 1988 with their behaviour in 1989. Note that comparisons of kit behaviour in the autumn with that of animals observed in the spring are difficult to interpret for a number of reasons. Differences could be due to season rather than age, and the kits were paired rather than being housed singly. Therefore, significant results will only be considered here if they occurred in the other types of comparison too.

In the Introduction, two types of change were described in the development of stereotypies in other species: establishment and emancipation. Mink stereotypy showed signs of increasing establishment with age in three ways. First, the variability of the behaviour decreased with time. The proportion of Restless behaviour made up of stereotypies was higher in adults than in kits; it increased in kits between autumn and the following spring; and it increased in adult females observed from one year 
to the next. Second, the frequency of the stereotypies increased. Kits had lower levels than adults, and their levels increased between autumn and the following spring; Rigid stereotypy levels were also higher in the multiparous than the primiparous females of 1988 (although this was not the case in 1989). Finally, in the adult animals, there was an association between high levels of stereotypy, low variability of stereotypy, and the behaviour being seen in more than one context. Thus by adulthood, high levels correlated with high Stereotypy/Restless scores, and mink whose stereotypies were seen outside the pre-feeding period had both higher levels of pre-feeding stereotypy, and higher Rigidity Indices. A decrease in variability with age, as measured by intra-individual variation in the speed of performance of stereotypy, has also been found in mink by Carlstead \& De Jonge (unpublished data).

Establishment in other species has been linked with lower interruptibility, as discussed in the Introduction. If this was behind the increasing frequency of the behaviour in the older mink, however, it did not mean the animals were oblivious to external stimuli. Even the adult mink, even when performing stereotypies at high speeds, would change the orientation of the behaviour, moving from one side of the cage to the other to follow the feeder as it passed by.

For mink stereotypies to be reliably compared with the developing and established stereotypies of other species, some further experiments need to be conducted. Established stereotypies have been reported to be inhibited by dopamine receptor antagonists but not by opiate receptor antagonists (Cronin et al., 1985; KenNes et al., 1988), and unlike younger forms of the behaviour, they cannot be inhibited by anxiolytic agents (FELDMAN \& Green, 1967; Duncan \& Wood-Gush, 1974). It would be interesting to see if mink stereotypies behaved in the same way, and if so, at what age or stage of development. In addition, further experiments would be necessary to test for the development of central control and to distinguish it from other developmental processes (see Mason \& Turner, 1993 for more details; also Groothuis, 1993).

The link, in adults, between increased establishment and the performance of stereotypy in contexts not associated with feeding is not as easy to explain as it might at first appear, as it does not seem to be due to straightforward emancipation. There are five reasons for believing that 
stereotypies did not develop first pre-feeding and then come to be emancipated. First, incidental observations were made of post-feeding stereotypies in kits as young as 10 weeks of age. The incidence of post-feeding stereotypy also did not increase after the age of six months. In six-seven month old mink, relatively high levels of post-feeding stereotypy were seen in individuals with little pre-feeding behaviour, and showing postfeeding stereotypy was not associated with having particularly unvarying behaviour. Finally, stereotypies performed in different contexts differed in form. There are two possible explanations for the link between the number of contexts and the frequency/variability of adult stereotypies. One is that stereotypies that are performed in other contexts become emancipated and then performed pre-feeding, thus increasing the levels of stereotypy in this period. The data from 1988's adults support this idea: individuals with post-feeding stereotypy have a greater proportion of Stationary elements in their pre-feeding stereotypies (Mann-Whitney $\mathrm{U}=$ $840, \mathrm{p}<0.05)$, and correspondingly fewer Longitudinal movements $(\mathrm{U}=$ $773.5, \mathrm{p}<0.01)$. However, the data from 1989 show no such significant differences, suggesting instead an alternative explanation: that individuals differ in their general propensities to develop stereotypy (MAson, $1991 \mathrm{~b}$ ), and that the number of contexts and the frequency/variability of the behaviour are independent products of this propensity.

Thus it seems that stereotypies are potentially performed in more than one context even at early stages of their development, and these movements may well first emerge in a number of different contexts. The following section considers the possible motivational bases of mink stereotypies in more detail.

Possible motivational bases for the stereotypies of mink.

All mink with stereotypies performed this behaviour in the run-up to feeding. The pre-feeding peak is similar to that of the stereotypies of other carnivores, such as captive bears (Meyer-Holzapfel, 1968; though $c f$. Weghsler, 1991) and fennec foxes (ÖDBERG, 1987). Note that this peak in stereotypy has not been superstitiously conditioned by the daily arrival of food. Mink fed ad lib. from a young age develop no less stereotypy than other mink, although the performance of their stereotypies is much more spread over the day (Gras, 1987; Hansen \& Hansen, 1992). Similarly, 
Staddon \& Simmelhag (1971) did not believe the pre-feeding stereotypies of their laboratory rodents to be superstitious (see also ROPER, 1983). Instead, appetitive behaviour may be a behavioural need which most mink could not help but perform. In the wild, carnivores have to show locomotor activity before they can obtain food, and they often remain motivated to perform hunting-like behaviour in captivity even though it is now unnecessary for feeding purposes (reviewed ToATEs \& JENSEN, 1991; see also Morris, 1964). This pre-feeding activity contrasts with the situation in pigs, who are by nature opportunistic foragers and whose stereotypies are performed after eating their often inadequate meals (e.g. Cronin et al., 1984). The sustained high levels of stereotypy on the day when the mink were not fed suggest that hunger is an important factor; and BiLdsøe et al. (1991) found that a 30\% reduction in food led to a tripling of mink stereotypy levels. The role of hunger in potentiating the performance of stereotypies resembles that in pigs (e.g. APPLEBy \& LawRENGE, 1987; Terlouw et al., 1991; Rushen et al., 1993).

In 1988's adults, Longitudinal movements were particularly associated with the pre-feeding period: if an animal's stereotypy was exclusively prefeeding, more of its stereotypy was likely to consist of these movements. De Jonge (unpubl. data) has also found that pacing shows by far the steepest increase in the run-up to feeding, compared to head-twirling and other stereotypic movements. In addition, Mason (1992a) found that male kits with the most behavioural signs of interest in food before the development of stereotypy went on to use Longitudinal movements to the greatest extent. Wild mink searching for prey move to and fro across a small area, usually less than $300 \mathrm{~m}$ across (GERELL, 1969), so perhaps the to-ing and fro-ing of the caged mink parallels the activity of the hunting animal. Thus the pre-feeding stereotypies of mink, and particularly the Longitudinal forms, may represent appetitive, food-searching behaviour. Amongst the adults of 1989, stereotypic use of the nestbox also rose as feeding-time approached. Why such a movement should be associated with feeding motivation is not clear, but it may be that it was simply an elaboration of longitudinal pacing.

However, not all mink stereotypies plausibly derive from appetitive behaviour. Elements such as head-twirls bear little resemblance to anything seen during normal hunting, and some animals' stereotypies were accompanied by squeaking, presumably not something done by a mink 
bearing down on its prey. In addition, stereotypies were seen in other contexts in addition to the pre-feeding period, such as when mink were paired for mating and apparently keen to separate (see also DE JONGE et al., 1986; de Jonge \& Carlstead, 1987).

Stationary movements such as head-twirling were particularly prevalent in stereotypies when food was not immediately expected. In both adults and kits in 1988, Stationary movements were more common postfeeding than pre-feeding, and in the kits the frequency of such movements declined over the morning as the expected time of food delivery grew nearer. Similarly, elements such as head-twirling do not show a pronounced pre-feeding peak (DE JONGE, unpubl.). What these movements actually represent is not clear. Stationary stereotypies always involved facing out of the cage, and so may be derived from attempts to escape. They were certainly the first unambiguous stereotypies to be seen in the mink, performed by highly aroused and probably frightened 10 week old kits when first moved to a new cage. DE JONGE (pers. comm.) also reports that head-twirling at mating time, when caged with another animal, is sometimes seen in mink that never normally do it. However, it is not clear why 'escape' movements should be relatively frequent in the quiet hours after feeding, when most mink are quietly resting and ocasionally taking mouthfuls of their food. Perhaps some mink found the lack of stimulation aversive, or perhaps the behaviour was disinhibited by the consummation of feeding motivation. Attempts to escape an enclosure have been postulated as the source of stereotypies in a variety of other species (reviewed by Rushen et al., 1993).

The typical form of stereotypy in the mink changed with sex and age as well as with context. The most consistent change with age was a decrease in the use of Stationary elements. The relative decline in the use of these elements with age may be because the mink became less motivated to escape, or because other forms of stereotypy came to predominate. There was, for instance, some evidence that Longitudinal movements increased in frequency with age. One difference that might be more trivially explained is the apparently age-dependent increase in the use of the nestbox. As females also consistently used the nestbox more than males, and 1990's kits used it more than 1988's, it may be that smaller animals and single-housed animals used the nestbox to a greater extent simply because they found access easier. 
Welfare significance.

Stereotypies are thought to indicate poor welfare because, amongst other reasons, they often derive from the behaviour of highly, persistently motivated animals. A high level of motivation sustained because the animal is unable to take effective consummatory action is synonymous with frustration (e.g. HiNDE, 1970, p. 415), and hence such animals may well be suffering. In addition, their development is thought to be encouraged by barren unstimulating environments that demand little variation in behaviour and that supply little in the way of behavioural competition. Such barren environments may well be sub-optimal for animals. (For a more detailed review see MAson, 1991a). In mink kits, stereotypy levels correlate with signs of poor welfare, such as relatively enlarged adrenal glands (MAson, 1992a). This suggests that the factors behind the development of stereotypies in mink are also responsible for poor welfare. Such factors may include the lack of opportunity to hunt and the lack of ability to escape from aversion, as discussed above, and the generally unstimulating nature of their cages. A number of studies do suggest that providing mink with more to do decreases their stereotypies. For example, adding objects to the cage which can be manipulated reduces stereotypy levels (Hansen, 1989; DE Jonge \& Nieuwenhuis, 1989; though $c f$. Jeppesen \& Falkenberg, 1990). Social interaction can do likewise: a female's stereotypies decrease after the birth of her litter (e.g. BILDsøE et al., 1990b), and increase again when the kits are removed from her (Heller, 1990).

However, the establishment of stereotypies may decrease the sensitivity with which they reflect states of reduced welfare. If the behaviour becomes more readily elicited and less easily interrupted, it may be slipped into and sustained even when the animal is not, say, in a state of high, frustrated, motivation (for more details see MAson, 199lb). This may explain why in the adults, and especially the multiparous females, stereotypy levels and signs of poor welfare no longer correlate (MAson, 1992a, b).

Site and sex differences.

The sex and site differences in the stereotypies of mink were pronounced. The higher level of stereotypy shown by the UK compared to the Dutch 
mink was remarkable, and there were also differences in form. Indeed some elements seem specific to different populations: somersaulting is never seen in the Dutch mink (DE JoNGE, pers. comm.), while stereotyped scratching at the cage wire, and rolling the head between the forelimbs, seem unique to Danish animals (Hansen, 1988; Bildsøe et al., 1990a). Aspects of husbandry could play a role. For example, the mink on the Dutch farm were always fed within the same hour from one day to the next, while on the UK farm feeding time was far less predictable. The Dutch mink were also fed twice a day, and because feeding was not mechanised it was a much quieter affair. Furthermore, 1990's kits were single-housed, while 1988's kits were still in male-female pairs. In addition, there may well be genetic differences between the two sites, as found in a Danish study of stereotypies in which mink from three different farms, with greatly differing levels of stereotypy, were housed together on a single site and only mated within their own lines. The three strains retained their different levels of stereotypy even though their housing conditions were now identical (JEPPESEN et al., 1990).

That females showed much higher levels than males is difficult to explain as they are considerably smaller (e.g. Birks \& Dunstone, 1985), and in the wild would have smaller territories (BIRks \& LinN, 1982; Dunstone \& Birks, 1985); one might therefore expect them to find the cage slightly less constraining. They may either have been more highly motivated to perform the behaviour patterns from which stereotypies arise (and hence may be more frustrated by life in captivity), or general behavioural and physiological differences might have increased the ease with which unvarying, repetitive sequences developed from the source behaviour in females (MASON, 1991b). One possible explanation is that past experience played a role. There is some evidence that being housed in pairs as kits may be detrimental to the female as the male can dominate her in the competition for food. Gaining relatively little weight during this period, and being caged with a bold rather than a timid male, predicted the development of stereotypies in young females on the Dutch site (MAson, 1992a).

Identifying mink stereotypies - theory and practice.

Stereotypies are defined as being rigid, repetitive, and with no obvious function, yet deciding on the exact criteria for classification (how repeti- 
tive is 'repetitive'?) is essentially arbitrary (e.g. Mason, 1991a, 1993). The behaviour of mink illustrates this well, as rarely were sequences completely unvarying, and their behaviour could be classified into three nested categories: Rigid stereotypy, Stercotypy, and Restless behaviour. I focussed on the middle category and chose to classify some sequences with unpredictable elements as stereotypies because of their predictable recurrence from day to day, and because there are no a priori reasons to exclude them given how little is known about these apparently functionless behaviour patterns. Restless behaviour (or Rigid stereotypy) may also have been an equally valid and useful focus of study.

Different stereotypic movements appearing in different contexts have been observed in sows (e.g. Cronin \& Wiepkema, 1984; Rushen, 1984, 1985; Wiepkema \& Schouten, 1992) as well as mink. Such heterogeneity within the stereotypies of a single species, in a single housing condition, indicates that when collecting data on stereotypies, descriptions should always be detailed (see also MAson, 1993), and based on form rather than solely on some secondary characteristic such as complexity ( $c f$. DE JONGE $e t$ al. 1986).

Conclusions and future work.

This study showed mink stereotypies to become less variable and more frequent with age, as expected from previous studies of stereotypies and other unvarying behaviour patterns. However, what precise developmental processes are responsible for this change, and what changes in neurological basis or emotional correlates also occur, needs further study. In addition, the role played by emancipation in influencing when particular movements are performed as the mink ages needs to be investigated in a detailed longitudinal study. This study also suggested possible motivational bases for some of the stereotypies of mink, although bizarre movements such as somersaulting remain mysterious, and more information is still needed. (For example, are the post-feeding stereotypies seen when all is quiet different from those seen when the mink are disturbed or apparently upset?) However, this study has generated specific hypotheses which can now be tested by varying aspects of the environment and/or the animals' motivational state. The knowledge can then perhaps be used to improve these animals' welfare. 


\section{References}

Anderson, M.C. \& Shettleworth, S.J. (1977). Behavioral adaptation to fixed-interval and fixed-time food delivery in golden hamsters. - J. Exp. Anal. Behav. 25, p. 33-49.

Appleby, M.C. \& LaWrence, A. B. (1987). Food restriction as a cause of stereotypic behaviour in tethered gilts. - Anim. Prod. 45, p. 103-110.

Berkson, G. (1967). Abnormal stereotyped motor acts. - In: Comparative psychopathology - animal and human (J. Zubin \& H.F. HunT, eds). Grune \& Stratton, New York, p. $76-94$.

- (1968). Development of abnormal stereotyped behaviours. - Devel. Psychobiol. 1, p. $118-132$.

- - \& Mason, W.A. (1964). Stereotyped behaviors of chimpanzees: relation to general arousal and alternative activities. - Percept. Motor Skills 19, p. 635-652.

Bildsøe, M., Heller, K.E. \& Jeppesen, L.L. (1990a). Stereotypies in adult ranch mink. Scientifur 14, p. 169-177.

$-\ldots,--\&--(1990 \mathrm{~b})$. Stereotypies in female ranch mink: seasonal and diurnal variations. - Scientifur 14 , p. 243-247.

,$----\&-(1991)$. Effect of immobility stress and food restriction on stereotypies in high and low stereotyping female ranch mink. - Behav. Proc. 25, p. 179-189.

Birks, J.D.S. \& Dunstone, N. (1985). Sex-related differences in the diet of the mink Mustela vison. - Holarct. Ecol. 8, p. 245-253.

- — \& Linn, I.J. (1982). Studies of home ranges of the feral mink. - Symp. Zool. Soc. Lond. 49, p. $231-257$.

Cooper, J. \& ODberg, F. (1991), The emancipation of stereotypies with age. - In: Applied animal behaviour: past, present and future (M.C. Appleby, R.I. Howell, S.C. Petherick, \& S.M. Rutter, eds). UFAW, Potter's Bar, p. 142.

Gronin, G.M. \& Wiepkema, P.R. (1984). An analysis of stereotyped behaviour in tethered sows. - Ann. Rech. Vét. 15, p. 263-270.

- - - - \& Hofstede, G.J. (1984). The development of stereotypies in tethered sows. In: Proceedings of the International Congress on Applied Ethology in Farm Animals (J. Unshelm, G. van Putten \& K. Zeeb, eds). KTBL, Darmstadt, p. 97-100.

— - - - \& vaN REE, J.M. (1985). Endogenous opioids are involved in abnormal stereotyped behaviours of tethered sows. - Neuropeptides 6, p. 527-530.

Draper, W.A. \& Bernstein, I.S. (1963). Stereotyped behavior and cage size. - Percept. Motor Skills 16, p. 231-234.

Duncan, I.J.H. \& Wood-Gush, D.G.M. (1974). The effect of a Rauwolfia tranquilizer on stereotyped movements in frustrated domestic fowl. - Appl. Anim. Ethol. 1, p. 67-76.

Dunstone, N. \& Birks, J.D. (1985). The comparative ecology of coastal, riverine and lacustrine mink, Mustela vison, in Britain. - Zeitschr. für Angewante Zool. 72, p. 59-70.

Feldman, R.S. \& Green, K.F. (1967). Antecedents to behaviour fixations. - Psychol. Rev. 74 , p. $250-271$.

Fentress, J.C. (1973). Specific and non-specific factors in the causation of behavior. In: Perpectives in Ethology (P.P.G. Bateson \& P.H. KLopfer, eds). Plenum Press, New York, p.155-224.

- - (1976). Dynamic boundaries of patterned behaviour: interaction and self-organisation. - In: Growing points in ethology (P.P.G. Bateson \& R.A. Hinde, eds). Cambridge University Press, Cambridge, p. 135-167.

- (1977). The tonic hypothesis and the patterning of behavior. - Ann. NY. Acad. Sci. 290, p. 70-395.

Fox, M.W. (1965). Environmental factors influencing stereotyped and allelomimetic behavior in animals. - Lab. Anim. Care 15, p. 363-370.

- (1971). Psychopathology in man and lower animals. - J. Am. Vet. Med. Assoc. 159, p. 66-77. 
Gerell, R. (1969). Activity patterns of the mink, M. vison Shreber, in southern Sweden. Oikos 20, p. 451-460.

Gras, B. (1987). Stereotype gedrag van nertsen. - COVP report, Het Spelderholt, Beekbergen, The Netherlands.

Groothuis, T. (1989). On the ontogeny of display behaviour in the black-headed gull: II. Causal links in the development of aggression, fear and display behaviour: emancipation re-considered. - Behaviour 110, p. 161-204.

- - (1993). The ontogeny of social displays: form development, form fixation and changes in context. - Adv. Stud. Behav. 22, p. 269-322.

Hall, M. \& Halliday, T. (1992). Behaviour and evolution. - Open University, Milton Keynes.

Hansen, C.P.B. (in press) Stereotypies in ranch mink: the effect of genes, litter size and neighbours. - Behav. Proc.

Hansen, S.W. (1988). Effect of variable cage sizes and lack of admission to the nestbox on the behaviour, physiology and production of mink kits. - In: Biology, Pathology and Genetics of Fur-bearing Animals (B.D. Murphy \& D.B. Hunter, eds). Unpublished proceedings of the IVth International Scentific Congress on Fur Animal Production, Toronto, p. 153-162.

- (1989). Activity in the daytime of lactating farm mink in cages with either water bath or net wire cylinder, - Poster at the International Ethological Congress, Utrecht.

- - \& Hansen, B.K. (1992). Effect of cage environment on the circadian rhythm, behaviour and food intake of farm mink. - Acta Agric. Scand.

Heller, K.E. (1989). Scientific aspects of fur-farming. - Unpublished report, Institute of Population Biology, University of Copenhagen.

- (1990). Stereotypies in ranch mink. - Paper given at Workshop on Stress and Abnormal Behaviour. Elsiner, Denmark. Sept. 1990.

- - \& JePpesen, L.L.J. (1990). Stereotypies in ranch mink. - Paper given at Workshop on stress and abnormal behaviour. Elsinør, Denmark. Sept. 1990.

Hinde, R.A. (1962). The Relevance of animal studies to human neurotic disorders. - In: Aspects of psychiatric research (D. Richter, J.M. TAnner, Lord TAYlor \& O.L. ZangwILl, eds). Oxford University Press, London, p. 240-261.

- (1970). Animal behaviour (2nd edition). - McGraw-Hill, USA.

Hutr, C. \& Hutr, S.J. (1970). Stereotypies and their relation to arousal: a study of autistic children. - In: Behaviour studies in psychiatry (C. Hutr and S.J. Hutr, eds). Pergamon Press, Oxford, p. 175-200.

Jensen, P., Algers, B. \& Ekesbo, I. (1986). Methods of sampling and analysis of data in farm animals. - Birkhauser Verlag, Basel.

Jeppesen, L.L. \& Falkenbero, H. (1990). Effects of play balls on pelt-biting, behaviour and levels of stress in ranch mink. - Scientifur 14, p. 179-186.

- -, Bildsøe, M., \& Heller, K.E. (1990). Production and abnormal behaviour. Scientifur 14 , p. 300 .

de Jonge, G. \& Carlstead, K. (1987). Abnormal behaviour in farmed mink. - Appl. Anim. Behav. Sci. 17, p. 375 (abstract).

_ - - _ - \& WiePKema, P.R. (1986). The welfare of ranch mink. (Transl. from Dutch.) COVP issue no. 08, Het Spelderholt, Beekbergen, The Netherlands.

Keiper, R. (1970). Studies of stereotypy function in the canary (Serinus canarius) - Anim. Behav. 18, p. 353-357.

Kennes, D., Ödberg, F.O., Bovquet, Y. \& de Rycke, P.H. (1988). Changes in naloxone and haliperidol effects during the development of captivity-induced jumping stereotypy in bank voles. - Eur. J. Pharmacol. 153, p. 19-24.

Kiley-Worthington, M. (1977). Behavioural problems of farm animals. - Oriel Press, London.

(1983). Stereotypes in horses. - Equine Practice 5, p. 34-40. 
Marler, P. (1991). Differences in behavioural development in closely-related species: birdsong. - In: The development and integration of behaviour (P.P.G. BATEson, ed.). Cambridge University Press, Cambridge, p. 41-70.

- -, Peters, S., Ball, G.F., Dufty, A.M. \& Wingfield, J.C. (1988). The role of sex steroids in the acquisition and production of birdsong. - Nature 336, p. 770-772.

Martin, P. \& Bateson, P. (1986). Measuring behaviour - an introductory guide. Cambridge University Press.

Martiniuk, R.G. (1976). Information processing in motor skills. - Holt, Rinehart \& Winston, New York.

Mason, G.J. (199la). Stereotypies: a critical review. - Anim. Behav. 41, p. 1015-1037.

- - (1991b). Stereotypies and suffering. - Behav. Proc. 25, p. 103-115.

- (1992a). Individual differences in the stereotypies of caged mink. - Unpublished $\mathrm{Ph}$. D. thesis, University of Cambridge.

- - (1992b). Stereotypy and welfare in mink. - Abstract in J. Anim. Sci. 70, suppl. 1, p. 158.

- - (1993). Forms of stereotypic behaviour. - In: Stereotypic animal behaviour: Fundamentals and applications to animal welfare (A.B. Lawrence \& J. Rushen, eds). CAB International, Wallingford, Oxon, p. 7-40.

- - \& Turner, M.A. (1993). Mechanisms involved in the development and control of stereotypies. - In: Perspectives in Ethology, Volume 10: Behavior and evolution (P. P. G. Bateson, P.H. Klopfer \& N.K. Thompson, eds). Plenum Press, New York, p. 53-85.

Meyer-Holzaprel, M. (1968). Abnormal behaviour in zoo animals. - In: Abnormal behaviour in animals (M.W. Fox, ed.). Saunders, London, p. 476-503.

Morris, D. (1964). The response of animals to a restricted environment. - Symp. Zool. Soc. London 13, p. 99-118.

Nieuwenhuis, C. \& de Jonge, G. (1989). Gedragsveranderingen van nertsen in een verrijkte omgeving. - De pelsdierenhouder, March issue, p. 114-118.

Norman, D.A. (1981). The categorization of action slips. - Psychol. Rev. 89, p. 1-55.

ODBerg, F. (1978). Abnormal behaviours: (stereotypies), Intro. to the Round Table. - In: Proceedings of the First World Congress on Ethology applied to Zootechnics, Madrid (Editorial Garsi). Industrias Grafices Espana, Madrid, p. 475-480.

- - (1986). The jumping stereotypy in the bank vole (Clethrionomys glareolus). - Biol. Behav. 11, p. 130-143.

- (1987). Behavioural responses to stress in farm animals. - In: The biology of stress in farm animals: an integrative approach (P.W.M. van Adrichem \& P.R. Wiepkema, eds). Martinus Nijhoff, Dordrecht, p. 135-149.

Roper, T.J. (1983). Schedule-induced behaviour. - In: Animal cognition and behaviour (R. S. Mellgren, ed.). North-Holland Publ. Co., p. 127-164.

Rushen, J. (1984). Stereotyped behaviour, adjunctive drinking and the feeding periods of tethered sows. - Anim. Behav. 32, p. 1059-1067.

- (1985). Stereotypies, aggression and the feeding schedules of tethered sows. - Appl. Anim. Behav. Sci. 14, p. 37-147.

- - Lawrence, A.B., \& Terlouw, E.M.C. (1993). The motivational basis of stereotypies. - In: Stereotypic animal behaviour: fundamentals and applications to welfare (A.B. LAWRENCE \& J. Rushen, eds), p. 41-64. CAB International, Wallingford.

Siegel, S. \& Castellan, N.J. (1988). Nonparametric statistics. (2nd ed.). - McGraw-Hill, New York.

Staddon, J.E.R. \& Simmelhag, V.L. (1971). The "Superstition" experiment: a re-examination of its implications for the principles of adaptive behavior. Psychol. Rev. 78, p. 3-43.

Stone, A.A. (1964). Consciousness: altered levels in blind retarded children. - Psychosom. Med. 26, p. 14-19. 
Terlouw, E.M.C., Lawrence, A.B., \& Illius, A.W. (1991). Influcnce of feeding level and physical restriction on development of stereotypies in sows. - Anim. Behav. 42, p. $981-992$.

Tontes, F. \& Jensen, P. (1991) Ethological and psychobiological models of motivation: towards a synthesis. - In: From animals to animats (J.A. Meyer \& S. Wilson, eds). MIT Press, Massachusetts, p. 194-205.

WeChSLER, B. (1991). Stereotypies in polar bears. - Zoo Biol. 10, p. 177-188.

Wiepkema, P.R., Broom, D. M., Duncan, I.J.H. \& van Putten, G. (1983). Abnormal behaviours in farm animals. - A report of the Commission of the European Communities, Brussels.

- - \& Schouten, W.G.P. (1992). Stereotypies in sows during chronic stress. - Psychother. Psychosom. 57, p. 194-199. 